\title{
EL P. ISLA A TRAVÉS DE LA BIBLIOTECA JESUÍTICO-ESPAÑNOLA DE HERVÁS
}

\author{
Antonio Astorgado Abajo \\ Universidad de Zaragoza
}

Después de diez años, A Rafa Olaechea, S. J. (+ Loyola, 1993).

\section{Introducción}

Con motivo de la preparación de la edición crítica de la Biblioteca jesuítico-española de Hervás y Panduro , nos dimos cuenta del cariño especial con que Hervás trata a varios de los más de quinientos ex jesuitas expulsos que escribían sobre las más diversas materias y del liderazgo de algunos de dichos ex jesuitas sobre el resto de los escritores (Astorgano 2004). Uno de esos líderes a los que el abate de Horcajo hace brillar es la figura del escritor leonés.

Como es sabido, Hervás se sirvió de las informaciones de sus compañeros ex jesuitas para sus investigaciones lingüísticas mediante un intenso carteo con bastantes de ellos, lo que le permitió ir adquiriendo copiosa información biobibliográfica sobre los mismos.

Por supuesto, no pretendemos agotar el inmenso fondo bibliográfico, tanto impreso como manuscrito, que produjeron los más de cinco mil ex jesuitas expulsos entre 1767 y 1816 en que volvió la mayoría de los supervivientes a España, ni examinar los 495 retratos bio-bibliográficos de los ex jesuitas

1. Lorenzo HERVÁS, Biblioteca jesuítico-española de los escritores que han florecido por siete lustros. Estos empiezan desde el año de 1759, principio del reinado del Augusto Rei Carlos III, y acaban en el 1793. Manuscrito muy deteriorado, conservado en el Santuario de Loyola. Edición crítica de Antonio Astorgano. Diputación de Cuenca, en proceso de elaboración. Citado sólo como (HERVÁS, Biblioteca). Agradecemos al P. Don José Martínez de la Escalera sus amables sugerencias al hilo de la lectura del artículo "Isla". 
dibujados en la Biblioteca, ni la abundante bibliografía que en los dos últimos siglos ha generado el P. Isla.

Hasta ahora nadie ha tenido en consideración la Biblioteca jesuítico-española, a la hora de estudiar al P. Isla. El único que la cita es Russell P. Sebold (1960 I: 12): "Los biógrafos [de Isla] son: Lorenzo Hervás y Panduro, S. J., en su Biblioteca jesuítico-española (1759-1793), inédita, en archivos privados".

El presente estudio tiene la reducida pretensión de presentar una de las primeras reseñas bio-bibliográficas del $\mathrm{P}$. Isla, tal vez la segunda después de la de Murr, tal cual aparece en la Biblioteca jesuítico española. Es una breve, pero completa biografía del P. Isla, redactada en sus líneas generales a lo largo de 1793 en Roma, aunque con sucesivas añadiduras hasta 1799, por uno de sus más eximios cofrades, el polígrafo Lorenzo Hervás y Panduro. Después de dos siglos de estudios bio-bibliográficos islianos, son pocos los datos nuevos que aporta para el investigador actual, pero la verdad es que después de leer el artículo de Hervás nos quedamos con un retrato suficiente del ilustre leonés, que era el objetivo de su Biblioteca jesuítico-española.

\section{Contexto temporal de la Biblioteca jesuítico-española de Hervás}

Hemos rotulado el artículo "Isla, José" con el número 107 del primer Catálogo (el de escritores con obra impresa) de la Biblioteca y está estructurado en tres partes, según el plan de trabajo de Hervás: biografía, obra impresa y manuscritos. Fue redactada a mediados de 1793, en uno de los momentos más reaccionarios por los que pasó la literatura española de la Ilustración, como repulsa a los excesos ideológicos de la Revolución francesa. Desde luego el moderado Hervás siempre fue un jesuita modelo, y por lo tanto contrario al pensamiento filosófico ilustrado francés (cuyos principales autores había leído), pero nunca se mostró tan fanáticamente antiilustrado como en esta época, como demostró sobradamente en la obra que redactará a continuación de la Biblioteca jesuítico-española. Nos referimos a las Causas de la Revolución de Francia en el año de 1789, y medios de que se han valido para efectuarla los enemigos de la Religión y del Estado, dedicada a su amigo y mecenas, el consejero de Castilla Tomas Bernad, fechada en Roma el 25 de marzo de 1794 (Hervás 1807).

Estas dos obras están relacionadas no sólo en el tiempo (redactadas las dos en menos de un año entre 1793 y 1794) sino en el espíritu antifilosófico y antirrevolucionario de Hervás, puesto de manifiesto por Javier Herrero (1971: 151 181), por otro lado bastante extendido en la literatura escrita en España en ese bienio, como ha estudiado Sala Valldaura (1995: 477-501).

En este ambiente antirrevolucionario, redacta Hervás su Biblioteca jesuíticoespañola, quizá con la intención de poner de relieve lo mucho que los jesuitas 
habían luchado contra los filósofos, padres de la revolución, y lo mucho que habían sufrido por ello. Y si algún jesuita había luchado y sido perseguido recientemente por defender a la Compañía de Jesús y por luchar contra los filósofos y los políticos regalistas, ese era el P. Isla. En el artículo "Isla", Hervás inserta palabras textuales del escritor leonés que tienen la finalidad específica de poner de relieve el "jesuitismo" del P. Isla y las virtudes de la Compañía. Por ejemplo, el episodio de las cartas recriminatorias de los superiores que Isla hace públicas en Pontevedra el día de la intimación del decreto de expulsión. También las expresiones textuales del P. Isla en la escena patética de la iglesia de Calvi: "Saldré para morir en la calle...". Lo mismo las palabras textuales que Isla le dirigió a la condesa Tanari suplicando la dote para la hija del causante de su prisión en Budrio entre 1773-1775. Como no podía ser de otra manera, tratándose del narrador Hervás, jesuita convencido y modélico, tanto la Compañía como Francisco José de Isla aparecen retratados sin ninguna tacha.

A finales de 1793, cuando Hervás estaba redactando sus notas sobre Isla, el padre Luengo (Diario XXVII-2, pp. 125-161) anota nuevas hostilidades de los filojansenistas en Madrid contra los jesuitas: la suspensión de la venta del libro El obispado del ex jesuita Bolgeni, íntimo amigo de Hervás; no se puede imprimir la obra del padre Isla contra el arzobispo José Javier Rodríguez de Arellano y había persecución contra La historia de la vida del hombre de Hervás, acusada nada menos que de filorrevolucionaria por el prólogo que puso al frente del tomo I (1789). Recordemos que a lo largo de 1793 y 1794 Hervás estaba seriamente enfrentado con Joaquín Lorenzo de Villanueva (Játiva 1757- Dublín 1837), protegido por el ministro de Gracia y Justicia, Eugenio de Llaguno, quien llegó a prohibir a Hervás que escribiese nada contra el Catecismo de estado, según los principios de la Religión (Madrid, Imprenta Real, 1793) del doctor Villanueva. Así como el ministro de Gracia y Justicia Manuel de Roda (Zaragoza 1707- San Ildefonso de la Granja 1782) se obsesionó con la posibilidad de que Isla atacase los postulados del gobierno, otro tanto le ocurrirá más tarde al ministro homónimo, Llaguno, con Hervás. Y no les faltaba fundamento al temor de los ministros, pues los dos jesuitas eran formidables intelectuales que conocían la lucha con sus enemigos los filósofos y jansenistas, como Isla había demostrado en sus apologías del jesuitismo en el exilio, y como Hervás demostrará al año siguiente con su Causas de la Revolución Francesa (1794).

Es evidente que Isla, Luengo y Hervás coinciden plenamente en las teorías del pensamiento jesuítico, lo cual no era desconocido por sus enemigos los filojansenistas, protegidos por el ministro Llaguno, desvanecidas ya las esperanza de un pronto regreso de los expulsos a España, según el rumor que circulaba en Italia en 1792, amparado por el gobierno del conde de Aranda. El pensamiento del padre Luengo coincide con el libro sobre las Causas de la revolución francesa que por esta época también estaba redactando Hervás y con las obras 
vindicativas de Isla en Italia (Memorial de las cuatro provincias españolas [1768], Anatomía del Informe de Campomanes [1767-1768] y la Anatomía de la Carta pastoral que, obedeciendo al Rey, escribió el Ilustrísimo y Reverendísimo Sr. D. Joseph Xavier Rodríguez de Arellano, arzobispo de Burgos [concluida a finales de 1772]), estudiadas por Enrique Giménez (1997a: 595607).

En resumen, para comprender el afecto con que Hervás redactó el artículo "Isla" de su Biblioteca, hay que tener en cuenta el momento de exaltación contrarrevolucionaria de España e Italia en 1793 y de reafirmación jesuítica de Hervás, coincidente con la que había tenido Isla y siempre tuvo Luengo. Aunque, como es lógico, el jesuitismo nunca fue monolítico entre los más de 5000 expulsos ni entre los más de 600 escritores ex jesuitas, ni su opinión coincidente totalmente con tal o cual compañero jesuita.

Parece que Isla fue lector de Hervás, quien había empezado a publicar su enciclopedia Idea dell'Universo en Cesena en 1778 y cuando Isla murió en 1781 ya tenía en las librerías casi una docena de volúmenes. Nos apoyamos en el hecho de que eran suscriptores el ilustrísimo marqués Pietro Tedeschi, de Ferrara (Isla vivía en el palacio de los Tedeschi de Bolonia) y también lo era el amigo común el abate Giuseppe Petisco, quien había sido el censor del FG, nombrado por la Compañía en 1757 (Bellettini 1998: 613).

\section{Las fuentes del artículo "Isla"}

Las únicas tres fuentes que reconoce Hervás para el artículo "Isla" son su experiencia personal en los escasos contactos que tuvo con el leonés, lo que había leído en el Journal del luterano Christoph. Gottlieh Murr y, finalmente, los datos recogidos en el tomo tercero del Ensayo de una Biblioteca de los mejores escritores del reinado de Carlos III, (Madrid, Imprenta Real, 1786) de Juan Sempere y Guarinos.

Hervás (1807: 354) concedía bastante importancia a Murr (1781) como fuente, pues también lo cita en las Causas de la Revolución francesa, precisamente en el capítulo titulado "Progresos de la secta filosófica desde el año 1753 hasta el de 1789. Congresos de filósofos y de jansenistas. Destrucción de los jesuitas por los filósofos con ayuda de los jansenistas. Proyectos filosóficos para destruir las monarquías", donde dice: "el luterano, informado no superficialmente de los medios y providencias de varios gabinetes para la expulsión de los jesuitas de Portugal, Francia y España, y para conseguir en Roma la total abolición de la Compañía Jesuítica, ha publicado no pocos anécdotos curiosos e interesantes en su voluminoso Diario (que es el más erudito que en Europa se publica) y principalmente en los dos primeros volúmenes de el dicho Diario", el cual se publicaba en latín y prestaba especial atención a asuntos jesuíticos, mediante biografías, anécdotas y cartas de políticos y escritores franceses, 
portugueses y españoles. Por ejemplo, en el artículo $V$ del tomo III Murr dedica 22 páginas a la vida del marqués de Pombal.

Por otra parte, Murr es fuente importante para Monlau (BAE, XV, p. XVII), y, a través de éste, de casi todos los estudios islianos posteriores. Don Pedro Felipe relata el incidente ocurrido con Murr, quien publicaba en Viena un Diario de la literatura europea, e insertó algunas noticias equivocadas sobre el Padre Isla. Con tal motivo le escribió desde Bolonia al diarista alemán una extensa carta (BAE, XV: 614-616) y Murr rectificó en el tomo X de su Diario. En fin, como resume Olaechea (1983: 105), Gottlieb von Murr fue quien ya en 1783 nos dejó perfilado el retrato de Isla.

El artículo "Isla" de Hervás, al recoger la información de Murr, asesorada por el mismo escritor leonés, se inserta entre los estudios islianos más clásicos que a lo largo de los dos últimos siglos han ido dibujando al personaje, por lo que es difícil que nos sorprenda por su novedad, precisamente porque su contenido ya es tradición, a pesar de permanecer inédito. Sin embargo, aporta ciertos detalles, que es conveniente comentar, por haber pasado desapercibidos.

Una segunda fuente de Hervás fue el artículo "Isla" de Sempere y Guarinos, que carece de introducción biográfica, de donde tomó algunos datos bibliográficos para el apartado de "obras impresas", cuya estructura u orden de las obras reseñadas parece seguir algo, si bien la descripción técnica de cada libro es más completa y amplia en Hervás. Sempere reseña nueve libros. El de Horcajo lo hace con doce, añadiendo los números 8 (Sumario de la historia eclesiástica y de la de España, en verso, por el P. Josef Francisco de Isla), 10 (Colección de papeles crítico-apologéticos, que en su juventud escribió el $P$. Francisco Isla contra el doctor don Pedro de Aquensa y el bachiller Don Diego de Torres en defensa del R. P. Benito Feixoo y del doctor Martín Martínez) y 12 (Cartas de Constantino Pupini, traducidas del italiano. Son varios tomos que se imprimían en Madrid").

Como dato curioso, el número 11 de los impresos (Vida y hechos de Blas Gil de Santillana; traducción del francés. 4 vols. en $8 .^{\circ}$ ) aparece con idéntica descripción en el número 4 de los manuscritos. Probablemente, Hervás había leído el deseo de Sempere en 1786 ("es de desear la impriman sus herederos") y también tendría noticias de que se había impreso en Madrid en 1787-1788, pero no había visto la edición.

Tampoco Hervás sigue el orden de Sempere, que aparece alterado de la siguiente manera (el primer número es el del orden de Hervás y el segundo el de Sempere): 1/1 (Día grande de Navarra), 2/2 (FG), 3/6 (Compendio de Historia de España de Duchesne), 4/3 (Cartas de Juan de la Encina), 5/4 (Reflexiones christianas) y 6/5 (Cartas familiares). Simplemente aludidos en Sempere están los impresos 7/7 (Vida del Gran Theodosio), 9/8 (Año Christiano) y 11/9 (Historia de Gil Blas de Santillana). 
Debemos descartar cualquier influencia de la biografía "oficial" del P. Juan José Tolrá (1803), redactada con ayuda de la hermana del P. Isla, doña María Francisca de Isla y Losada, y publicada en 1803, no sólo porque es diez años posterior, sino también porque Hervás no alude a ella en el artículo "Tolrá" (n. ․ 240), en el que, ciertamente, se mencionan cuatro estudios biográficos suyos, pero no el de Isla (1. Compendio della vita di Santa Olimpia Vedova, e diaconessa della chiesa di Constantillopoli. 2. Homini illustri della famiglia Belvi. 3. Elogio e relazione de' falti militari del generale Laudon; y 4. Vita di Antonio Bermejo).

\section{La parte biográfica del artículo "ISLA, Josef Francisco de", en la Biblioteca de Hervás}

Es en la parte biográfica donde más se nota la admiración de Hervás por el P. Isla, aunque presenta varios errores, comprensibles por el inexorable paso del tiempo en los recuerdos, por la pertenencia a distintas provincias jesuíticas (Castilla y Toledo) y por la distinta residencia de ambos, Isla en Bolonia y Hervás en Forli-Cesena.

Junto con el hábito y la afición a la escritura, las personalidades de Isla y Hervás presentan rasgos comunes que, además de curiosos, pueden explicar otras cosas. Por ejemplo, ambos eran vascófilos convencidos y admiradores del P. Larramendi, residente en Loyola, a quien Isla trató, con seguridad, cuando el leonés fue predicador en San Sebastián entre 1746 y 1750 (Legarda 1955: 61-73; Pérez Picón 1964; Astorgano 2003b; Astorgano 2003c y Jurado 1992: 12).

En cinco líneas, Hervás condensa la etapa isliana anterior al ingreso en la Compañía. Tomando los datos del epitafio ("Qui Natus Villavidane in Legionensi regno Die XXIV Martii Anni CICDCCIII"), acepta el 25 de marzo como fecha de nacimiento, cuando en realidad fue el 25 de abril. Sólo le interesan las ideas fundamentales y desecha leyendas muy arraigadas entre los historiadores jesuitas, como la de que nació mientras su madre iba a una peregrinación. Don José de Isla, padre, como administrador del señorío de Rivesla, residía en Vidanes al nacer su primogénito. Transcurrido no mucho tiempo, tomó la residencia en Valderas, lugar donde pasa su infancia el novelista; en septiembre de 1716 fue trasladado a Astorga con los cargos de corregidor de la ciudad y juez de los lugares de tal jurisdicción y, finalmente, dos o tres años después, a Galicia, como ha demostrado Albano García Abad (1969: 39-55). 
En unas diez líneas Hervás sintetiza los 42 años que van desde el 21 de abril de 1719 en que ingresó en la Compañía ${ }^{2}$, en la casa de Santiago, hasta marzo de 1761 en que se retiró a Pontevedra, quizá para sosegar a la Inquisición, que había condenado el FG y al mismo Isla por solicitud sacramental el 31 de mayo de 1760 (A. H. N., Inquisición, leg. 3272; Pinta Llorente 1979: 33-59). Pudiéramos pensar que el conquense no tenía datos concretos de estos años, pero pudo haberlos solicitado a cualquier jesuita castellano, como el P. Petisco, amigo de Isla. Hervás destaca la faceta de predicador sobre la de profesor y piensa que predicando Isla obtuvo un doble beneficio: moderó su carácter y puso en práctica la reforma de la oratoria sagrada que defenderá en el FG. No sabemos por qué Hervás destaca la actividad evangélica de Isla en Valladolid, la cual fue corta (desde marzo de 1750, en que abandona San Sebastián, hasta abril de 1751, en que es destinado como prefecto de la Congregación de los Caballeros de Salamanca). Sólo se nos ocurre la explicación de que en el gran colegio de San Ignacio de Valladolid, donde solían recalar los ex provinciales y moralistas tan reputados como Pedro Calatayud, había más control sobre sus miembros por parte de la Compañía que en otros lugares, incluido el noviciado de Villagarcía de Campos, regido por el "comprensivo helenista" P. Francisco Javier Idiáquez.

Lógicamente, Hervás no especifica las "vivezas y trasportes de la juvenil fantasía" de Isla, pero podemos suponer que se referiría a las diversas polémicas en las que participó, causadas por su genio satírico, y a los citados deslices sentimentales de los que habla Pinta Llorente (1979).

La narración del viaje de Isla al destierro coincide esencialmente con las noticias antiguas que dan Luengo (Diario I y 2002), el Memorial del propio Isla (1999) y su biógrafo P. Tolrá (1803), y con las modernas de Constancio Eguía (1947, 1948, 1951 y 1955), Enrique Giménez (1997b) y otros.

2. Josef de Isla fue "consagrado de epístola" el 19 de octubre de 1727, junto con otros nueve ordenandos, en el oratorio privado del palacio episcopal de Salamanca, por el obispo de Salamanca, don Silvestre García Escalona. ADS, Libro Becerro de las órdenes generales y particulares, menores y mayores que el Ilustrísimo Señor Don Silvestre García Escalona, por la Gracia de Dios y de la Santa Sede Apostólica obispo de esta ciudad de Salamanca, del Consejo de Su Magestad, celebró en su capilla episcopal y oratorio privado.... Años 1714-1729, sig. C-2-4, fol. $149 \mathrm{r}-149 \mathrm{v}$.

El 26 de octubre del mismo mes fue consagrado "de Evangelio": "En la ciudad de Salamanca, a 26 de dicho mes [octubre de 1727] y el dicho Ilustrísimo Señor Obispo, etc., por ante mí, su secretario [Joseph Lucas Rodríguez] ordenó de Evangelio a Joseph de Isla" junto a otros nueve ordenandos (Ibídem). Dos días después, el 28 de octubre, fue ordenado de misa: "Y en 28 de dicho mes [octubre de 1727] ordenó de misa a los siguientes: P. Nicolás de Puga, P. Santiago González, Joseph de Isla, Domingo Clemendi, Fernando Aludo, Juan Losada, Juan Ibarrola, Joseph de la Torre, Francisco Ignacio García y Joseph de Jauregui. Y para que conste lo firmé, Joseph Lucas Rodríguez, Secretario". ADS, Libro Becerro... Años 1714-1729, sig. C-2-4, fol. 149r$149 \mathrm{v}$. 
Hervás también es bastante fidedigno en la etapa de la vida de Isla que va desde la salida del puerto de La Coruña (mayo de 1767) hasta su asentamiento en Crespelano (en los alrededores de Bolonia) a fines de 1768 (Eguía 1948: 597-611). Es probable que el 29 de junio de 1767 un desconocido, pero inquieto, Hervás conversase por primera vez con el famoso P. Isla, (cuando Hervás era profesor en el Colegio Imperial de Madrid, Luengo estaba en Pontevedra), a juzgar por lo que dice el P. Luengo (2002: 204). Por primera vez estaban "bastante reunidas tres provincias enteras: la de Andalucía, Castilla y Toledo", y no les faltó permiso para visitarse mutuamente: "No es necesario decirlo para que se entienda, que ha habido todo este día un bullicio y confusión muy grande pero muy inocente, alegre y festivo. La mayor parte de las visitas han sido a la Provincia de Toledo".

El encuentro de Isla con el párroco de Calvi no aparece en el Diario de Luengo ni en el estudio específico de Martínez Gomis (1997: 679-690), pero debió ocurrir a lo largo del 19 de julio de 1767, como afirma Conrado Pérez Picón (1981: 460) (no sabemos por qué Martínez Gomis [1997: 684] dice que "durante los días 13 o 14 de julio de 1767 tuvo lugar el desembarco de los jesuitas de las provincias de Castilla y Andalucía en Calvi"), cuando desembarcaron en Calvi los viajeros del "San Juan Nepomuceno". Luengo (2002: 251) escribe el domingo 19 de julio: "Después de dos meses cumplidos que nos embarcamos en el puerto de La Coruña y en el mismo día en El Ferrol, en el navío de guerra el San Juan Nepomuceno, hemos saltado hoy a tierra en esta ciudad de Calvi de la isla de Córcega". El relato de Hervás, cuya experiencia en su llegada a Córcega fue bastante más positiva que la de Isla y Luengo por la mayor humanidad del comandante del convoy de la provincia de Toledo, don Francisco Vera (quien se negó a dejarlos en Ajaccio sin unas condiciones de habitabilidad mínimamente dignas, por lo que el desembarco no tuvo lugar hasta el 23 de septiembre) coincide con el de Luengo, excepto en la apreciación del carácter del capitán del "San Juan Nepomuceno", en el que viajaron Isla y Luengo, José Beanes. El relato de Luengo también es patético: "Nadie nos acompañó al salir del navío; nadie ha cuidado de que tengamos casas o habitaciones en que dormir y nadie ha pensado en que tengamos hoy [19 de julio] alguna cosa que comer [...]. Quedamos, pues, solos y abandonados en este muelle de Calvi sin saber qué hacernos" (2002: 253-254).

Los Colegios de Pontevedra (el de Isla) y de Santiago (el de Luengo) estuvieron muy cercanos y sin embargo las noticias del autor del FG que aparecen en las páginas corsas del Diario son muy escasas, por la única razón de que Isla vivía aislado su vida bastante cómodamente, dentro de las circunstancias, en casa del único párroco de Calvi.

Evidentemente, a pesar del patetismo con que Hervás narra la anécdota de la iglesia de Calvi, Isla era una excepción privilegiada, como lo había sido viajando en compañía del capitán del "San Juan Nepomuceno", porque el 
provincial P. Ignacio Enrique Ossorio Guzmán y Espínola (Grajal 1713- Bagni della Porreta, 1778), noble leonés, hijo del conde de Grajal y hermano del marqués de Alcañices, procuró agrupar en una misma vivienda a los jesuitas procedentes de un mismo colegio de España.

Respecto al episodio del Lazareto de Génova, el momento de mayor intimidad que Hervás tuvo con el P. Isla durante toda su vida, y siguiendo la narración del P. Luengo (2002: 746), sabemos que los castellanos Ilegaron a dicho Lazareto el 10 y 11 de octubre de 1768 y el 13 lo hace la de Toledo ("En efecto, han venido hoy a este Lazareto las dos Provincias de Andalucía y Toledo"). Ese mismo día Luengo (2002: 745-746) nos hace una descripción del Lazareto ("Es sin duda una obra grande, bastante magnífica [...], hay almacenes inmensos para depositar las mercancías y mucha habitación para gente, pero no es tanta que pueda servir de decente alojamiento para mil quinientos o setecientos hombres honrados, fuera de que no se nos ha dado toda, pues por lo menos han reservado una cuarta parte de la habitación, ya para alguna gente que está ahora haciendo su cuarentena, ya para lo que se pueda ofrecer mientras que estemos nosotros aquí"), donde forzosamente la convivencia de Isla y Hervás fue muy estrecha.

En buena lógica, se produjo un "alegre y bullicioso alboroto", que sólo "podrá entender quien acierte a concebir mil seiscientos hombres, encerrados en una casa no grande, de diferentes Provincias" (Luengo 2002: 750). Aunque Hervás dice que los jesuitas españoles estuvieron "encerrados por más de un mes" en el Lazareto, lo cierto es que los primeros llegaron a partir del día 11 de octubre y el 21 del mismo mes empiezan a abandonarlo. El día 20 escribe Luengo (2002: 757): "Hoy es el último día que estamos todos juntos los de las tres Provincias en este Lazareto, más famoso por haber sido habitado de tantos centenares de jesuitas que por todos los sucesos que en él se hayan visto". El día 21 confirma la noticia: "Trescientos de la Provincia de Castilla salimos hoy del Lazareto para Sestri; después, a su tiempo, nos seguirán los demás de nuestra Provincia, que son más de otros tantos, y habiéndose de seguir después, como ya se dijo en otra parte, la Provincias de Andalucía y Toledo, fácil es de entender que en todo el invierno no se limpia el Lazareto de jesuitas y que a muchísimos les cogerá un tiempo bien malo en el viaje por tierra" (Luengo 2002: 760). Es por tanto, difícil precisar, en las narraciones de Luengo y Hervás, el día exacto en que el P. Isla tuvo conocimiento de la edición desautorizada de la segunda parte del FG y de la entrevista que relata Hervás, en la que nos siembra la duda sobre el número de tomos del FG. Con certeza fue a lo largo de octubre de 1768.

La estancia de Isla en Bolonia es bastante conocida, por su correspondencia y estudios posteriores (Giménez 1996; Eguía 1932 y Eguía 1933), por lo que sólo incidiremos en algunos detalles más Ilamativos. Hervás no identifica al "venerable" que fue criticado por Isla y que será motivo de su prisión en 
Budrio. Sabemos que el tal venerable fue el obispo de México y después de Burgo de Osma, Juan de Palafox (Fitero 1600- Burgo de Osma 1659), cuya canonización defendían tan ardorosamente los regalistas y filojansenistas, protegidos por el gobierno de Madrid, como se oponían a ella los jesuitas. Esta es la razón por la que, despectivamente, Hervás ni lo cita por su nombre. El mismo Isla narró la causa de su detención: "Mi delito fue haber dicho, después de muy provocado con dicterios contra la Compañía, que cuando ésta no hubiese hecho otro servicio a la Iglesia, que oponerse dentro de los debidos términos a la beatificación del venerable Palafox, me parecía que por solo él merecía no ser abolida. No dije más ni se me hizo cargo de otra cosa" (Budrio, 8 de agosto de 1773, al P. Vicente Olcina). Al respecto Menéndez y Pelayo comenta sobre el obispo Palafox que se da "el caso no poco chistoso de ser volterianos y librepensadores los que más vociferaban y más empeño ponían en la famosa canonización" (Heterodoxos, lib. VI, c. II).

Hervás cree la versión del incidente dada por Isla, la cual resalta su intachable conducta en el mismo, y difiere bastante de la de otras fuentes, según las cuales la conversación fue tenida en casa del mariscal Welf, conde de Pallavicini, quien había invitado a comer a Isla. Durante el almuerzo había surgido como tema de conversación la cuestión de la beatificación del venerable Palafox y el dueño de la casa comentó que quizá fuera demasiada la firmeza con que los jesuitas se habían opuesto a ella, lo que motivó una airada respuesta de Isla, mientras se levantaba de la mesa y se despedía con descortesía, poniendo de relieve el profundo desprecio tradicional del jesuitismo hacia Palafox (Giménez 1997a: 591).

Hervás resalta el episodio de la dote conseguida por Isla para la hija de su perseguidor, para poner de relieve la generosidad del leonés, como hace notar Sebold (1960 I: 42). Lo más novedoso de Hervás es la encadenación de los hechos, que ponen de relieve la existencia de dos acusadores, pues normalmente se suele hablar de un solo acusador, generalmente genovés. Hubo dos, el genovés y el español Fernando Coronel, y la hija dotada fue la del italiano, como advierte Olaechea (1983: 109). Monlau (BAE, XV, pp. XV-XVI) transcribe las palabras textuales de la condesa Tanara (o Tanari), que coinciden exactamente con la conversación del texto de Hervás.

El detalle de la modulación en yeso de la cara del cadáver de Isla también es recogida por Monlau, lo que demuestra, una vez más, que tuvo la misma fuente que el abate de Horcajo (BAE, XV, p. XXII).

\section{El perfil psicológico de Isla, según Hervás}

La caracterización sicológica de Isla es tomada por Hervás del epitafio de Isla, reproducido por Murr y más tarde en el P. Diosdado Caballero (1814). Había sido redactado por el P. Petisco (Ledesma 1724- id. 1800), gran latinista 
y traductor de la Biblia, suscriptor de la enciclopedia Idea dell'Universo de Hervás y su corresponsal en Bolonia. Por ejemplo, Petisco le suministró los primeros textos en eusquera en abril de 1783 (Astorgano 2003c) y en 1789 Hervás (1789: 158) alaba su gramática escolar griega: "En los años pasados publicó el P. Petisco un compendio gramatical de la lengua griega ${ }^{3}$, que es bastante bueno para uso de las escuelas públicas". No nos consta que Hervás tuviese comunicación con D. Antonino de Soto Valcarce, el último compañero de Isla, y por lo tanto la fuente más inmediata para conocer las postrimerías de la vida del escritor leonés.

El P. Petisco no se quedó corto en los elogios de su amigo Isla ("In patria oratoria Tullium,/ In historia Livium,/ In lyricis ac ludicris Horatium") y ahora Hervás recoge los mismos elogios. Si Petisco había escrito que Isla era de "Mentis/ Amplae, sublimis, apertae,/ Ad omnes scientias natura comparatae,/ In omnibus fere excultae", Hervás afirma que "era dotado de talento grande y propio para ser excelente en todo género de ciencias". Si Petisco lo había calificado de "Viro/ Ingenii/ Lepidi, foecundi, perpoliti,/ Eleganti varietate amoenissimi", lo mismo Hervás ahora ("su fantasía era sobresaliente, y si de ella se hubiera dejado arrastrar hubiera inundado la república literaria de romances, poesías y de otras obras de placer y amenidad"). Hervás destaca la contradicción que Isla siempre vivió entre su doble condición de hombre y literato, dado a la ironía, y su sometimiento a las reglas estrictas del jesuitismo ("Los superiores de Isla juzgaron no ser combinable el desahogo de su gran talento poético con la continua ocupación de los ministerios apostólicos y el magisterio de la ciencias sagradas; y por esto únicamente no dejaron de darle algunos avisos de corrección"), aspecto obviado por Petisco ("Eximia pectoris ingenuitate,/ Ac inculpata morum probitate,/ Intimis carus,/ Exteris probatissimus").

Escueto, pero bastante completo, es el perfil socio-psicológico que Hervás hace de Isla, pues va más allá de lo estrictamente literario para decirnos que fue un buen profesor de filosofía y de teología y un erudito que dominaba varias lenguas cultas. No parece interesarle la descripción física, ni insiste demasiado en el lenguaje gracioso, propio del archiconocido genio satírico del leonés, resaltados por Monlau (BAE, XV, pp. XXII-XXIII).

Curiosamente el perfil psico-sociológico de Isla, hecho por Hervás, coincide bastante con el del su perseguidor, el comisario Fernando Coronel, pues ambos destacan el "espíritu bullicioso" y apasionado del leonés, el cual "se deja llevar demasiado de su natural elocuencia y es bastante libre en la expresión, [...]. Conozco bien el espíritu bullicioso de Isla y cuánto se deja llevar de sus pasiones en los casos que se ofrecen" ${ }^{4}$.

3. Nota de Hervás: "Gramática griega por el P. Joseph Petisco, jesuita. Villargacía, segunda edición, 1764, 8. 으.

4. AMAAEEM, Santa Sede, leg. 486, Coronel a Moñino, Bolonia, 30 de octubre de 1773. 


\section{Producción literaria impresa de isla reseñada por Hervás en el artículo "ISLA, Josef Francisco de", de la Biblioteca de Hervás}

El abate de Horcajo reconoce que estaba poco informado de la obra de Isla, porque debía dar noticias desde Italia de la producción literaria de un escritor cuya mayor parte había sido escrita en España y hacía tiempo. En efecto, la descripción bibliográfica presenta lagunas, tanto en la parte impresa como en la manuscrita.

Hervás lamenta la pérdida de numerosas obras de Isla, debido a las persecuciones de su ajetreada vida. De todas las pérdidas islianas, parece que la más dolorosa fue un manuscrito relacionado con las causas de la Revolución Francesa, asunto sobre el que, al parecer, el abate de Horcajo ya estaba proyectando escribir meses después su famoso ensayo. Desde luego, hoy nos parece que es aventurada la supuesta visión profética que Hervás le atribuye a la Historia política de los parlamentos de Francia de Isla, nada menos que ocho tomos escritos antes de 1767, pero el abate conquense hablaba en serio, pues meses después escribirá (primera mitad de 1794), sin hacer ninguna referencia a la perdida obra de Isla: "En Francia los jansenistas concibieron esperanza de la destrucción de los jesuitas con el apoyo y el favor de los parlamentos, declarados sus protectores y temibles al rey. Los jansenistas y filósofos desde el 1752 dieron coraje a los parlamentarios y realce a su autoridad con el aplauso popular que les procuraron conseguir" (Hervás 1807 I: 340). Lógicamente después de la destrucción de los jesuitas venía la de las soberanías.

Hervás no concede importancia a la producción literaria anterior al FG ("Hasta la edad de 50 años escribió muchos opúsculos poéticos, cuyo paradero se ignora"), aunque sabemos que era muy propenso a empuñar la pluma desde cuando era estudiante y a participar en obras poéticas colectivas. Por ejemplo, el abate conquense ignora la participación de Isla en La Juventud triunfante (1727).

La obra Día grande de Navarra no apareció "anónima", como dice Hervás, quien cita la segunda edición o "reimpresión" (la primera siempre ha sido muy difícil de localizar) de la que hay numerosos ejemplares, "corregida y aumentada con algunas piezas curiosas del mismo autor, las que se notan a la buelta", de la que existen al menos tres ediciones con igual pie de imprenta, pero que en el título reflejan diferencias ortográficas. En efecto, el Triunfo del amor y de la libertad es un opúsculo descriptivo de las fiestas de la coronación de Fernando II de Navarra y VI de España, que, como Hervás, apoyándose en su experiencia ("oí yo contar"), y Murr, es calificado por José Jurado (1992: 12) como "una juguetona bufa a las autoridades del reino de Navarra, emboscada casi toda ella bajo la forma de empalagosa apología o elogio de cada una de dichas autoridades. La treta, si así fue ella, pues Isla (y lógicamente los retratados) negó siempre con gran ardor que lo fuera $(F G, I$, viii, 7$)$, motivó el desplazamiento del escritor a San Sebastián 
(julio de 1747 a marzo de 1750), en donde se ocupó, como responsabilidad primaria, de confesar y predicar" ${ }^{5}$.

\subsection{Comentarios sobre Fray Gerundio}

Lógicamente, el abate conquense comenta más ampliamente el FG (impreso n. 2 de su lista) que el resto de las obras de Isla, con ciertas exageraciones para encomiar al venerable leonés. Por ejemplo, la rapidez de la venta de la primera impresión del tomo I, que fue rapidísima, pero no tanto como para que se vendiesen dos mil ejemplares en un solo día (fueron 1500 en tres días) ${ }^{6}$.

También hay equivocaciones, inevitables cuando se trata de recordar conversaciones tenidas 25 años antes, como la de "tomo", por "libro", pues sabido es que el FG que conocemos consta de seis libros (no seis tomos como dice Hervás) y de dos partes de tres libros cada una, equivalentes a dos tomos. Es posible la interpretación, menos probable, de que Isla le confesase a Hervás que pensaba alargar su novela hasta los seis tomos, novela que por su estructura episódica podría continuarse indefinidamente.

Hervás comienza confesándonos algunas intimidades, relativas al FG, extraídas de su relación personal con Isla en el Lazareto de Génova durante el mes que pasaron juntos en octubre de 1768. El abate conquense, quien había sido profesor en el Seminario de Nobles de Madrid entre 1764 y diciembre 1766 y pudo seguir de cerca el revuelo que el primer tomo del FG había suscitado, no resistió la curiosidad de saber su continuación (recordemos que precisamente en esos días le había Ilegado la noticia a Isla de la publicación en Francia, clandestina y desautorizada, del segundo tomo) y el leonés le resume el argumento de todo el FG. El plan total de Isla parece que no coincide con el conocido del FG y realmente viene a dar la razón a los que piensan que en la novela hay mucho mayor influjo del Quijote que de la novela picaresca. Sabido es que FG solamente predica dos sermones y medio y que la novela termina de una manera brusca cuando el protagonista se estaba preparando para predicar entera una Semana Santa, según su habitual estilo barroco. Comparemos las palabras de Hervás con las que Isla anuncia la tercera non nata parte del FG, para ver que la diferencia fundamental está en el factor que le vuelve el buen juicio a FG. Según Hervás fueron "la experiencia y madurez que dan los años y los avisos de religiosos sabios":

"y últimamente con la experiencia y madurez que dan los años y con los avisos de religiosos sabios lo proponía iluminado en la verdadera manera de anunciar la palabra divina. Se ignora

5. De manera parecida opinan Pedro Felipe Monlau (BAE, XV, p. XXVI), Sebold (1960: 32) y Juan Luis Alborg (1975: 264-265), entre otros.

6. Equivocación que pudo haber copiado de Sempere y Guarinos (1786: 128), una de sus fuentes confesadas, quien dice: "Esta obra fue recibida con el mayor aplauso, como lo manifiesta el haberse vendido todos los ejemplares de ella en veinte y cuatro horas". 
el fin que hayan tenido los tomos de la vida de Fray Gerundio que el señor Isla dejó inéditos, mas no es creíble que hayan perecido" (HERVÁS, Biblioteca).

Según la edición princeps, la conversión de FG a la correcta oratoria fue "efecto de no sé qué libro convincente que la divina Providencia le puso en las manos" y se vería en la "Tercera Parte", no escrita, salvo en los supuestos "seis tomos" de Hervás (Jurado 1992: 938-39).

José Jurado (1992: 939, nota 12) destaca una variante del manuscrito Baretti, y por lo tanto posterior a la edición de 1768 y al encuentro con Hervás en el Lazareto de Génova, según la cual la lectura del FG fue el libro que devolvió la cordura al propio Fray Gerundio:

"Y concluye el señor Abusemblat sus apuntamientos con la conversión de fray Gerundio al verdadero modo de predicar, efecto de no sé qué libro convincente que la divina Providencia le puso en las manos, compuesto por un Padre Tal [el mismo Isla], que fue desterrado en su vejez de su patria".

Resumiendo, en la primera redacción de 1758 Isla no había concretado la causa de la "conversión" de FG ("un libro convincente", de procedencia desconocida). En septiembre de 1768 los causantes eran "religiosos sabios" y en 1771 pudo concretarle a Baretti la causa fusionando las ideas anteriores: FG se convirtió gracias a la lectura del libro de la historia de FG, compuesto por un religioso "desterrado y temeroso" (según Isla, en 1771). FG cambia a base de reflexionar sobre sus propios errores. ¡Eso sí que es aprender de la propia experiencia personal, aunque haya tenido que ser retratada por mano ajena!

Como bibliófilo, Hervás, nada amante de la retórica escolástica, se preocupa mucho de los aspectos técnicos del libro y de su azarosa historia editorial, poco de su parte novelesco-satírica y nada de la didáctica (la que viene a ser un tratado de oratoria sagrada).

El polígrafo conquense comete varias imprecisiones, incluso sobre las experiencias vividas en el Lazareto de Génova, causadas por el paso del tiempo: los 25 años que van desde 1768 a 1793. Como hemos dicho, no se imprimieron dos mil ejemplares, sino 1500, que se agotaron en tres días y no en uno. Hervás parece confundir los seis libros de que constan los dos tomos conocidos del FG con seis tomos y tan convencido estaba de esta idea que, ignorando "el fin que hayan tenido los tomos de la vida de Fray Gerundio que el señor Isla dejó inéditos", no cree que hayan perecido y los incluye entre los manuscritos de Isla, "celosamente ocultos" (el ms. n. ${ }^{\circ} 3$ de su relación), pero de existencia cierta. ¡Ojalá que cualquier día nos encontremos con otros cuatro tomos del FG, autógrafos e inéditos, que sean continuación del manuscrito 2574 de la BNM, el único original del FG conservado! Nos tememos que no tendremos esa suerte.

Respecto a la recepción en España del FG remitimos a los estudios de José Jurado (1982: 544-580; 1985: 137-165 y 1992: XI-XXII) y de Joaquín Álvarez Barrientos (1991: XI-XXII). Ahora sólo procuraremos concretar la edición del FG 
que vio Hervás. Creemos que el conquense manejó la edición que José Jurado (1992: 56) identifica como la de"1770-1768. t. I y II. Edición francesa. A ambos tomos les faltan los nombres de lugar y de imprenta; y el t. I además omite el de autor". El estampado de los dos tomos se hizo, probablemente, en Bayona y no en España, como piensa Hervás. Por lo tanto, el abate de Horcajo tuvo en sus manos la edición príncipe del tomo II, justamente desautorizada por Isla, porque es una impresión precipitada y sumamente descuidada, cargada de innumerables incorrecciones y con frecuentes lagunas ${ }^{7}$.

\subsection{La primera traducción inglesa del FG, según Hervás}

Hervás se extiende al comentar a la traducción inglesa del FG, atribuida a Thomas Nugent y también a John Warner, e impulsada por Giuseppe Baretti, quien residía habitualmente en Londres y fue a visitar a Isla a Crespelano, donde, como es sabido, se hallaba instalado en el palacio veraniego del conde Grassi, desde finales de 1768. Hemos señalado que desde el otoño de ese año Isla conocía que había aparecido la ya aludida edición furtiva y defectuosa de la segunda parte del Gerundio, y Baretti quería publicar en Londres, en español, una edición completa de la novela, la cual no llegó a hacerse (Sebold 1960 I: 40-41). Con este fin, Isla corrigió el ejemplar de la edición de 1758 y el manuscrito de la segunda parte del Gerundio, de mano ajena, que pertenecían a Baretti, introduciendo a la vez algún cambio para adaptar la obra al gusto inglés. Baretti tuvo también un papel importante en la publicación de la versión inglesa de la novela, y, además, inspiró a Isla su traducción del poema burlesco de Passeroni, El Cicerón.

A principios de abril de 1771 Isla ya tenía corregida y "añadida" la versión del FG inglesa, para "dar al mundo una edición herética, o por mejor nombre anglicana, de mi querido frailecico", según una carta del leonés reproducida por Baretti (1980: 32).

Este manuscrito se conserva en la Biblioteca Nazionale de Turín y sus "añadiduras" han sido inteligentemente aprovechadas por José Jurado (1992: 61) en su edición crítica del FG.

Las relaciones entre Isla y Baretti continuaron cordiales después de la publicación londinense del FG, pues, a principios de 1773, Isla envió a D. Juan Benito Caffarena, de Génova, una Apología del Fray Gerundio, dirigida a D. Joseph Baretti, secretario de la correspondencia extranjera de la R. Academia Británica (AGS, Gracia y Justicia, 671).

7.Tanto disgustó la impresión a Isla que, desconociendo al impresor y corrector, "mandaría yo dar doscientos azotes al que la estampó, cuatrocientos al que la corrigió y ochocientos al que la costeó" (BAE, XV: 612). 
Hervás parece conocer mejor la versión inglesa que la española y observa algunas deficiencias: "En esta edición el traductor dejó la crítica contra el Barbadiño y algunos episodios". Opinión corroborada por Jurado (1992: 60).

El polígrafo manchego, apoyándose en el traductor inglés, hace notar la contradicción de los inquisidores que, primero, alabaron claramente el FG, para, después, prohibirlo. "Uno de los inquisidores" podría hacer referencia al mismo inquisidor general José Manuel Quintano Bonifaz, a quien intentó, infructuosamente, dedicar su obra Isla. Entre "los mismos inquisidores", podría incluirse al trinitario calzado y calificador de la Inquisición, fray Alonso Cano, uno de los censores que aprobó el $\mathrm{FG}^{8}$.

El abate de Horcajo acude a sus recuerdos personales para hacer un paralelismo entre la amarga experiencia del destierro de Isla y la del suyo propio, y así poder explicar el extravío del manuscrito original del tomo II del FG y la proliferación de copias, de muy diferente fiabilidad. Tanto para Isla como para Hervás la confiscación de los manuscritos en 1767 fue una experiencia de dolor imborrable, de manera que en este mismo año de 1793 califica el hecho de "robo". Escribe en el Viaje Estático (Hervás 1793b: 128-129):

"Empecé a escribir esta grande obra [El gobierno, costumbres, ciencias y religión de los habitantes de la luna] en mi juventud, estando en España, en donde al embarcarme para Italia perdí, o, por mejor decir, me robaron todos los materiales de ella, con otra Historia completa de una visita que había hecho a los reinos de Plutón, en compañía de personajes de diferentes naciones".

\subsection{Las polémicas sobre el FG, según Hervás}

Hervás también habla de memoria, y con brevedad, cuando alude a las polémicas que se suscitaron inmediatamente después de publicarse el primer tomo del FG, al cual Isla debió defender contra José Maymó y contra el capuchino Ribes, resumidas por Olaechea (1983: 108). Lógicamente, Hervás, profundo admirador del P. Larramendi y en magníficas relaciones con los socios de la Bascongada, omite cualquier referencia a la polémica de Isla con los "Caballeritos de Azcoitia". Como ha resumido Jorge Chen (1999: 206), el hilo que une todas estas críticas hostiles al FG consiste en que se acusa a Isla de reformular el estilo grave, propio del tema religioso, utilizando procedimientos que denotan tono burlesco que "echa a perder toda la seriedad requerida para persuadir a los malos predicadores".

Refrescando su memoria con la ayuda de la Biblioteca española de Sempere y Guarinos, Hervás alude a la buena recepción que el FG tuvo en el extranjero,

8. En concreto fray Alonso Cano termina su censura aludiendo a la necesidad del FG, idea que Hervás pone en boca de los inquisidores: "éste libro sólo falta, como otros muchos sobran", (Jurado, 1992: 80). 
confesada por el propio Isla cuando escribía en 1771, que su FG aún había metido más bulla en Italia que en España (Olaechea 1983: 108). En el extranjero, si seguimos a Hervás, el FG sólo cosechó elogios.

\subsection{Otros impresos de Isla}

\subsubsection{El Compendio de Historia de España de Isla}

Ni Sempere ni Hervás recogen la primera edición. Sempere (1786: 130-131) reseña una edición "corregida y enmendada de orden del Consejo, Madrid, 1782, en las oficinas de Hilario Santos Álvaro. Dos tomos en 8.․ . De esta obra se han hecho varia ediciones, no siendo menos apreciable por las notas del $\mathrm{P}$. Isla, que por el mérito de la traducción". Añade Sempere que Isla es uno de los pocos buenos traductores que había en España, "como lo acreditó no solamente en esta obra, sino también con la traducción de la Vida del Gran Theodosio, escrita por el obispo Flechier, y la del Año Christiano del P. Croiset".

El Compendio de Historia de España de Isla tuvo la primera edición en 1754 (Amberes). En Madrid, Joaquín Ibarra lo reimprimió en 1758, 1759 y 1764. Tuvo otra por los Herederos de Martínez en 1761 en Pamplona.

Hervás se refiere a la reimpresión de 1764, que apareció en Madrid, cuando él era profesor del Colegio de Nobles, por lo que es posible que la poseyese: Compendio de la historia de España, escrito en francés por el $R$. $P$. Duchesne. Traducido en castellano por el P. Francisco de Isla. Con algunas notas críticas que pueden servir de Suplemento, por el mismo Traductor. Madrid, 1764. Por Joaquín Ibarra. 2 vols. $15 \mathrm{~cm}$. Ya estando desterrados, verá la luz otra vez el Compendio (Madrid, en la imprenta de P. Marín, 1779, 2 Vols.; $15 \mathrm{~cm}$.), señal de la mucha demanda que continuaba teniendo, como manual escolar, pues de lo contrario las autoridades madrileñas (en especial Campomanes) se hubiesen opuesto a su reimpresión, por ser obra de jesuitas.

Conviene no confundir esta traducción de Isla con la casi simultánea que del mismo libro hizo el también jesuita P. Antonio Espinosa. En un raro caso de descoordinación jesuítica, los dos consocios tradujeron la misma obra y la publicaron con meses de diferencia. El P. Isla se vio obligado a dar alguna explicación, que puede leerse en Sommervogel (IV, cols. 655-686). Reconoce que la traducción del P. Espinosa es anterior, pero justifica la aparición de ambas por sus diferencias. Isla piensa que la suya es una traducción literal, Ilena de notas históricas y críticas y aumentada con los acontecimientos hasta 1742. La del P. Espinosa es sobre todo una paráfrasis, sin notas y con un apéndice de los sucesos acontecidos desde 1735 a 1749.

La verdad es que Hervás piensa lo contrario y que la versión del P. Espinosa es más pedagógica. El abate de Horcajo había alabado el Compendio de la historia de España de Duchesne, con ciertos reparos a la traducción de Isla, y lo 
había recomendado como manual escolar de historia de España, en el tomo II de la Historia de la vida del hombre (1789: 250-251), donde, una vez más, el conquense se nos muestra como un magnífico pedagogo:

"Es excelente el [Compendio de historia de España] que Duchesne escribió en francés y tradujeron bien en español Isla y Espinosa. Sería de desear que se hiciese otro compendio semejante de los dominios ultramarinos de España, con un apéndice en que se notasen sus conquistas actualmente sujetas a otras naciones. Asimismo, al Compendio histórico de España por Duchesne convendría añadir algunas notas, que omitió Isla y son necesarias para indicar los puntos substanciales de cronología e historia, que son dudosos, y los autores que los tratan con la mejor crítica".

Hervás juzga buenas las dos traducciones, pero parece que prefería la de Espinosa. La de Isla es reseñada "con algunas notas críticas" y en el artículo "Espinosa, Antonio" (art. n.․ 67 de la Biblioteca) el abate de Horcajo hace notar que la de Espinosa "añade un Compendio geográfico de España". El conquense nunca alude a la descoordinación jesuítica, sino que recomienda indistintamente las dos traducciones, aunque trató mucho más al Padre Espinosa, tanto en Madrid como en Murcia, en cuyo colegio ambos fueron sorprendidos por el decreto de expulsión de 1767.

Según el retrato de Hervás, el murciano Antonio Espinosa, "rector durante muchos años del Seminario de Nobles de Madrid", era un buen humanista, un eficaz pedagogo, varias veces felicitado por los reyes Fernando VI y Bárbara de Braganza "por la instrucción de los seminaristas nobles y el acertado gobierno de Espinosa", y un competente traductor del francés, por lo que es comprensible el enfado de Isla cuando se enteró de que el P. Espinosa se le había adelantado en la traducción del Compendio de Duchesne, además con "un compendio geográfico de España".

\subsubsection{Año Christiano}

Sempere (1786: 130-131) parece ser la fuente de la breve reseña del Año Christiano, pues el magistrado alicantino afirma que "los once primeros meses de éste los tradujo el P. Isla; pero no el de Diciembre, que está publicado y trabajado por otra mano".

Tal vez comenzada en Valladolid hacia 1750, Isla va a dedicar a la traducción de los Exercices de Piété pour tous les jours de l'année (Lyon, 1712-1720) del P. Jean Croiset muchos años, aunque con largas interrupciones; redactó doce tomos en traducción muy libre y con intercalaciones de vidas de santos del propio Isla. Hervás simplemente dice que la traducción del tomo XII no es del P. Isla.

Edición accidentada, según Palau, pero que tuvo numerosas reimpresiones en el siglo XVIII y posteriormente. El primer tomo se imprimió en Salamanca, con censuras de Eugenio de Colmenares y de Juan Ignacio Guerrero, ambos 
jesuitas. El segundo en Villagarcía y los demás en Madrid. Perdido el manuscrito del tomo XII, la versión impresa del mismo (1773) se atribuye a Enrique de la Cruz Herrera (Aguilar Piñal, 1986, IV, n. 4334). Isla confiesa en carta al P. Nieto (Pontevedra, 20 de septiembre de 1762) su intención de traducir y publicar los 18 tomos del Año Christiano: "y aunque pensé continuar ahí [Villagarcía] la impresión de esta grande obra, que se compone de dieciocho tomos, refrexionándolo mejor, hallé que se me había de doblar el coste, por ser necesario después trasladarse a Madrid para la encuadernación...", (Pérez Picón 1983: 108).

Hasta ahora, se ha creído que Joaquín Benito de Castellot la continuó hasta el tomo XVIII, pero sin atribuirle el citado tomo XII. Sin embargo, Félix Latassa (1885) también le atribuye a Castellot el tomo XII y especifica, convincentemente, otras traducciones suyas de Croisset (los tomos XIII al XVIII del Año Cristiano), de cuya obra era verdadero especialista: "3.ㅡ- Traducción del tomo XII del Año Cristiano del Padre Croisset, con que completó esta versión, que hasta el tomo XI había hecho el P. Josef Francisco de Isla. Se estampó en Madrid, en $4 . .^{\prime \prime \prime}$.

Obsérvese que Latassa considera como traducción independiente el disputado tomo XII del Año Cristiano, enmarcada dentro de una serie de traducciones del mismo Castellot. Especifica perfectamente la continuación del Año Cristiano hasta el total de los 18 tomos, lo que denota un buen conocimiento de la obra de Croisset y de su traductor Castellot. Si tenemos en cuenta la amistad de Isla con el inquisidor general Francisco Pérez Prado y Cuesta (Burgo de Osma 1677Madrid 1755), obispo de Albarracín-Teruel desde 1732, en cuya diócesis había nacido Castellot, y la pertenecía de ambos a la Inquisición, además de la admiración hacia Croisset, la afirmación de Latassa cobra verosimilitud. Monlau (BAE, $X V$, p. 33) incluye al inquisidor Pérez Prado entre los "personajes elevados" con los que mantenía correspondencia y estimulaban al P. Isla, como "amigo que le había tratado y estimaba mucho", a que abandonase las traducciones para dedicarse a la composición de obras originales. Es lógico deducir que, perdida la traducción isliana del tomo XII, otro clérigo y buen traductor, Castellot, muy relacionado con el amigo común el inquisidor Pérez Prado, continuase la traducción de la obra, cuya actividad literaria primordial era precisamente la de traducir.

Resumiendo, si el proyecto del P. Isla fue la traducción unitaria de los dieciocho tomos del Año Christiano, no parece lógico que se buscase un traductor aparte para el tomo XII, sino que fuese el mismo que tradujo los tomos XIII al XVIII.

9. Según Latassa (1885): "Castellot (D. Joaquín Benito)._- Nació en Escorihuela, de la Comunidad de Teruel, antes de la mitad del siglo XVIII. Fue Capellán Doctoral de S. M. en la Real Capilla de la Encarnación de Madrid y visor General de las librerías por el Consejo de la Suprema Inquisición. Al estudio de Artes y Teología, en cuya facultad tomó el bonete de Doctor, unió el de las buenas letras, conocimiento de idiomas y varia literatura". 


\subsubsection{Restantes impresos de Isla}

Hervás cita otros ocho impresos islianos (los números 4, 5, 6, 7, 8, 10, 11 y 12 de su relación), de los cuales, sólo los dos últimos (n. 11 [Vida y hechos de Blas Gil de Santillana] y 12 [Cartas de Constantino Pupini]) fueron redactados en Italia. Son dos traducciones, una del francés y otra del italiano, que eran consideradas oficiosa y públicamente en Bolonia como la única producción literaria italiana de Isla durante sus catorce años de exilio, a juzgar por una lista, anónima y bastante incompleta, de obras escritas por los ex jesuitas en el destierro, que circulaba por dicha ciudad hacia 1786, recogida entre los Papeles Varios (XV: 254) de Luengo.

El abate de Horcajo reseña una edición muy posterior de El héroe español, pues la primera tiene dedicado el tomo I en Segovia el 31 de diciembre de 1730 y el tomo II en la misma ciudad el 21 de marzo de 1731. Isla habla de "sacada" y no de "traducida", términos explicados en la carta a Murr de octubre de 1781 (BAE, XV: 614b).

En el olvido de Hervás y de Sempere quedaron traducciones como los Dialogi de senectute et amicitia, libro escolar que Isla redactó a petición de su amigo José Petisco en 1760. Olvido lógico, pues según Menéndez y Pelayo, "este libro de clase es, sin duda, el menos conocido de sus trabajos" (cita en Pérez Picón 1983: 103).

Finalmente notar la ausencia, entre los impresos de Isla, de la Juventud triunfante, la cual no fue desconocida por Hervás, sino que se la atribuye al $P$. Adrián Antonio de Croce (art. n. 58 del primer catálogo de la Biblioteca): "7. En la obra intitulada La juventud triunfante, publicada en Salamanca en las fiestas de la canonización de San Luis Gonzaga y San Estanislao de Kostka, el P. Croce trabajó buena parte". La participación de Isla en La juventud triunfante ha sido precisada por Martínez de la Escalera (1981) y Pérez Picón (1983: 9395) la considera como "la representación gráfica que el P. Isla hace de la teoría de la letra con sangre entra", en contraposición de la buena pedagogía jesuítica de la humanidades. Sabemos que fue una obra colectiva, entre otros, de los jesuitas Adrián Antonio de Croce, Francisco Javier Idiáquez, José Antonio Butrón y del P. Luis de Losada, a quien se le suele adjudicar la obra, por ser el profesor de mayor fama del momento. Hervás se la atribuye al P. Croce, pero no dice nada del P. Isla, a pesar de que este la reivindica poco antes de morir, en carta a su hermana, fechada en Bolonia el 21 de octubre de 1781, diciendo que había escrito casi la mitad del libro, que consta de 409 páginas en 4.․

\section{Manuscritos reseñados por Hervás en el artículo "ISLA, Josef Francisco de" de la Biblioteca jesuítico-española.}

Hervás comienza recordando la antes aludida pérdida de muchos manuscritos de Isla, "por sus circunstancias críticas", y añade que deben existir algunos 
ocultos, que no reseñará, porque sólo lo hará de los que le consta su "certidumbre", la cual, después de dos siglos no ha sido acreditada en algunos. Por ejemplo, todavía no nos consta la existencia de los ocho tomos de la Historia política de los parlamentos de Francia, estudio profético, según Hervás, sobre la Revolución Francesa. Pérez Picón (1983:107-109) parece identificar esta obra reseñada por el conquense con la "obrita secreta", alabada por el mismo Isla en carta al P. Francisco Nieto, como "la menos mala que ha salido de mis manos" (Pontevedra, 20 de septiembre de 1762). Si Hervás había escrito que esta obra "se admiraría como la historia políticamente profética del miserable estado actual de Francia", Pérez Picón (1983: 109) lamenta que "se haya perdido esta obrita; pero se vería obligado el mismo autor a destruirla, porque en aquellos años cercanos a la expulsión de los jesuitas, podía servir a los enemigos de cuerpo de delito".

Por el mismo temor, serían destruidos los tres tomos de la traducción de la Histoire du Paraguay de Pierre-François Charlevoix (París, 1757) que en 1762 pensaba publicar en Villagarcía (Pérez Picón 1983: 107).

Además, su fuente bibliográfica, Sempere (1786: 131), prácticamente no dice nada sobre los manuscritos de Isla: "También dejó al tiempo de su muerte la Historia de Gil Blas de Santillana, la que es de desear impriman sus herederos, como algunas otras obras, de las cuales, aunque existen, no he podido adquirir noticia más individual".

En resumen, el apartado de "manuscritos" es bastante deficiente desde todos los puntos de vista. En primer lugar, incluye obras que en 1793, cuando Hervás redactaba su Biblioteca jesuítico-española, ya habían visto la luz, como el n. ${ }^{\circ}$ 4 (Vida y hechos de Gil Blas de Santillana). Además la lista es corta (sólo cinco mss, cuando Giméz y Martínez Gomis (1996) enumeran 13 mss. islianos redactados en Italia) e imprecisa ("5. Algunos tomos de obras, ya poéticas y ya satíricas, contra personas irreligiosas o de religión dudosa"). El único manuscrito que aporta alguna información concreta es el n.․ 2 (Crítica de la carta pastoral que monseñor Dn. Josef Rodríguez de Arellano...).

\section{El jesuita P. Ramón Isla}

Hervás también reseña brevemente al hermano jesuita del P. Isla, con bastantes más imprecisiones que en el artículo de Francisco José, empezando por el lugar de nacimiento, que nunca pudo ser Vidanes, pues sabemos que el $\mathrm{P}$. Isla fue hijo único de madre y que en 1724 don José de Isla Pis de la Torre, su padre, estaba ocupando el cargo de juez de hijosdalgo en Ortigueira, villa al norte de La Coruña, y que ese mismo año muere doña Ambrosia Rojo, a los 61 años de edad. En 1726, don José, padre, ya se había establecido en Santiago de Compostela, donde se casó en segundas nupcias con doña María Rosa Losada, pariente del P. Luis de Losada, y de ella tuvo nueve hijos más (Albano García 
Abad, p. 55), de los que merecen ser recordados María Francisca, con la que el novelista mantuvo constante correspondencia, y el reseñado Ramón que ingresó en la Compañía.

Sólo añadir algunas precisiones al polígrafo conquense. Ramón Isla nació en Santiago el 30 de agosto de 1730, entró la Compañía en 1747 y murió joven en Burgos el 26 de julio de 1765, cuando más prometía y "hubiera hecho extraordinarios progresos si en la más fresca edad no hubiera desaparecido", en palabras de Hervás. De sus publicaciones gerundianas habla Uriarte (n. ${ }^{\circ} 6389$ ). Dejó además un Cursus philosophicus, un tratado de Gracia y 12 cuadernos de sermones.

\section{Conclusiones}

La parte biográfica del artículo "Isla" de Hervás nos parece más interesante que la bibliográfica, a excepción de las curiosas observaciones que hace sobre la recepción que tuvieron los dos tomos del FG en España e Inglaterra. Presenta bastantes imprecisiones bibliográficas, lo que demuestra que el abate de Horcajo no fue lector asiduo del leonés. No obstante, se aprecian detalles que denotan admiración hacia el autor del FG, no sólo por ser jesuita, sino también por estar ambos encuadrados en el sector más conservador del jesuitismo expulso, aunque integrados en la sociedad de su tiempo, a la que critican y pretenden educar y reformar, en algunos aspectos, con sus escritos.

Al estudiar la vida y obra de cualquiera de los más de seiscientos escritores jesuitas expulsos es importante considerar sus circunstancias, pues estas influyen decisivamente en cada una de sus personalidades, en el sentido más orteguiano del concepto. Cuando las circunstancias son tan convulsivas como las que les tocó vivir a los hijos de San Ignacio en la segunda mitad del siglo XVIII, la necesaria adaptación para poder sobrevivir literaria y físicamente fue constante, y a veces profunda, contradictoria y sorprendente.

Decimos esto porque en la misma temporada (años 1793-1794) encontramos a Hervás escribiendo la Biblioteca jesuítico-española, a mayor gloria de la Compañía, y las Causas de la Revolución Francesa, con un furibundo ataque a los jansenistas y filósofos, y, al mismo tiempo, plegarse mansamente a las órdenes del filojansenista ministro de Gracia y Justicia, Eugenio de Llaguno, con la única finalidad de salvar la publicación castellana de la Historia de la vida del hombre y las otras partes de su enciclopedia, Idea del universo (Viaje Estático, El Hombre físico y Catálogo de las lenguas) ${ }^{10}$.

10. El Consejo de Castilla había prohibido la introducción del tomo I, publicado en 1789, a instancias de Joaquín Lorenzo Villanueva quien había acusado a Hervás de "ateísta" y a sus ideas de "sistema infernal" (prólogo del Catecismo de Estado). Ver todo el Expediente en AHN, Inquisición, leg. 19.164, núm. 1012. Zarco Cuevas (1936: 41-44). 
Algo parecido ocurre en algunos momentos con la contradictoria personalidad del P. Isla, perfectamente estudiada por Olaechea en el estudio varias veces citado. Isla desenvainó la espada de su genio polémico en Bolonia en 1772 cuando escribió, con un nombre figurado, una dura "Anathomía" (disección) de la Carta Pastoral que (obedeciendo al rey Carlos III, es decir, a los fiscales Campomanes y Moñino) había publicado el arzobispo de Burgos, don José Xavier Rodríguez de Arellano, contra el sistema teológico-moral de los jesuitas. Se trata de un conjunto de 30 cartas, en las que Isla va sajando, sin anestesia alguna, los tumores thomístico- regalistas del prelado burgalés (Olaechea 1983: 109).

Cuatro años más tarde, en 1776, vemos al P. Isla en bastante buena actitud respecto a Moñino, el instigador directo de la supresión de la Compañía. A diferencia de la postura de Campomanes, quien siempre se mantuvo distante al tratar con los jesuitas (Astorgano 2003a), el conde de Floridablanca adoptó un talante más dialogante con los mismos, puesto que ya en 1776 varios ex jesuitas españoles, se supone que encuadrados en el sector jesuítico próximo ideológicamente al regalismo encarnado por el Colegio de San Clemente, tuvieron la intención de dedicarle un libro de composiciones poéticas, que Moñino no aceptó, con motivo de su exaltación al empleo de Secretario de Estado en Madrid. Al parecer, el P. Isla, como un regalista más, participaba en dicho homenaje de manera destacada, que a duras penas Luengo puede disimular o justificar en su relato.

Según Luengo (Diario, X: 643-653) el libro tuvo su origen en la incapacidad intelectual de los colegiales españoles de San Clemente de Bolonia, quienes acudieron a los jesuitas para que les compusiesen varias poesías. Resalta la incongruencia e impertinencia de los colegiales de San Clemente de Bolonia al solicitar a los ex jesuitas que cantasen poéticamente a uno de los enemigos más encarnizados de la Compañía ("hacer que los jesuitas empleen sus talentos y su trabajo en hacer versos para elogiar y hacer grande y famoso a Moñino, a este hombre que en los cuatro o cinco años que ha estado en Roma no ha respirado sino fuego, odio, rabia, furor y veneno contra ellos y contra su Compañía, y no ha pensado ni aún soñado otra cosa que en despreciarlos, calumniarlos, oprimirlos y arruinarlos a ellos y a su religión, y en fabricar y levantar hasta las nubes su grandeza [la de Moñino], elevándose sobre sus ruinas [las de los jesuitas]").

En consecuencia, el padre Luengo, que estaba rabiosamente en contra de que los ex jesuitas colaborasen en el homenaje a Moñino, desacredita a los participantes, en cierta medida, al no considerarlos representativos del verdadero espíritu jesuítico, y se ve obligado a hacer un verdadero equilibrio mental para no descalificar al "acalorado" P. Isla, quien, a pesar de que había desobedecido la orden gubernamental de no escribir sobre la expulsión de los jesuitas, redactando su "Anatomía" sobre el informe de Campomanes (1768) y sobre la 
Carta Pastoral de Rodríguez de Arellano (1772), atacando duramente la política gubernamental española, encabeza en 1776 este homenaje a Floridablanca, primer ministro del mismo gobierno:

"A la frente de todas las composiciones se pone, como se debe suponer, un pomposo título en el que se dice que el Colegio de San Clemente le presenta aquel corto obsequio, y después una expresiva y lisonjera dedicatoria, que la ha compuesto nuestro famoso José Francisco de Isla. Este buen anciano, que ama ciertamente la Compañía, es uno de aquellos que entran en el Colegio de San Clemente, y por esta causa se ha acalorado alguna cosa en este negocio, y, además de la dedicatoria del libro, ha compuesto una larga rima española, y entre los elogios que da en ella a Moñino, a lo que me asegura quien la ha leído, es darle de algún modo su Espíritu Santo, que en Roma le haya hablado también a la oreja. A este modo o de otro poco diferente delirarán los otros poetas" (Diario, X: 643-653).

El libro de composiciones poéticas fue dedicado, finalmente, al cardenal Boxadors, porque, informado anticipadamente Moñino de su contenido, puso reparos en que se le dedicase la colección de composiciones poéticas ${ }^{11}$. El padre Luengo exculpa al padre Isla insinuando la sospecha de que Moñino rechazó el libro, porque contenía la dedicatoria del padre Isla, al que tenía cierto temor, y que la dedicatoria que finalmente apareció en el libro fue obra de algún ex jesuita aragonés (Diario, XI: 54-57).

Por último, es bastante difícil responder a la cuestión clave del grado de conocimiento que Hervás tenía de la vida y obra del famoso P. Isla. A juzgar por el artículo que glosamos, da la impresión de que Hervás se interesó por el leonés durante los primeros años del destierro, pero después de la supresión de la Compañía y de la muerte de Isla, el abate de Horcajo, alejado de Bolonia en Forli, en Cesena y en Roma, se despreocupó del autor del FG, por lo que, llegado el momento de escribir el artículo "Isla" se vio precisado a documentarse, y aún así salió con bastantes errores. Ciertamente había leído el FG, al que cita sin precisión, tanto en la versión castellana como en la inglesa. Por ejemplo, cuando reseña las Oraciones fúnebres del antiguo provincial P. Salvador Osorio, "a las que, en el tomo 2 de la Historia de Frai Gerundio, se alude diciéndose que parecerían bien en París" ${ }^{\prime 2}$. Asimismo cita, con cierta precisión, una nota de la traducción del Compendio de la historia de España de Duchesne para justificar los lazos de Isla con Valderas, "a la cual pasaron sus padres poco después al su nacimiento y, por eso, Isla en una nota al Compendio de la historia de España [de Duchesne], que tradujo, Ilama a Valderas nuestra adoptada patria".

11. Aplausos poéticos que en la fausta promoción al empleo de primer Secretario de Estado y del Despacho Universal en la persona del Excelentísimo Señor Don Joseph Moñino, conde de Floridablanca y Caballero del Real y Distinguido Orden de Carlos III, dedica rendidamente el Real Colegio de San Clemente de los Españoles de Bolonia, al Eminentísimo y Reverendísimo Padre Fray Juan Thomás de Boxadors, Cardenal de la Santa Romana Iglesia y Maestro General del Orden de Predicadores. En Bolonia, MDCCLXXVII [1777]. En la Imprenta de Lelio de la Volpe, con las licencia necesarias. Es en folio pequeño y tiene 81 páginas.

12. Hervás cita de memoria, y por lo tanto de manera imprecisa. La única mención del P. Salvador Osorio en la novela ocurre en la Segunda Parte, libro V, capítulo IV (Jurado 1992: 776). 
También Hervás se preocupó de documentarse bibliográficamente ("las noticias que he adquirido"), pues los impresos que realmente vio (los nueve primeros números de su lista) están correctamente fichados, bastante mejor que en Sempere y Guarinos, con el editor, lugar y año de edición, número de volúmenes y formato, aunque sin el orden cronológico que sería esperable, quizá porque desconocía cuándo habían aparecido las primeras ediciones de algunos libros. En el resto de los impresos (números 10 al 12, que no "vio") y en los manuscritos, procura dar el número de volúmenes y el formato, con algunas imprecisiones ("varios tomos", "algunos tomos", etc.). Hervás pudo haber sido más concreto, acudiendo a alguno de sus corresponsales en Bolonia, como el P. Petisco, pero recordemos que la Biblioteca jesuítico-española fue redactada bastante apresuradamente, en menos de un año a lo largo de 1793. Por otra parte, sabemos que los amigos del P. Isla ya habían sentido la dificultad y la necesidad de recopilar datos bibliográficos de su obra, por lo que le sugirieron que redactase una lista de sus obras, cosa que no pudo llevar a cabo por sorprenderle la muerte.

Las imprecisiones que encontramos en el artículo "Isla" se deben a fallos de memoria cuando relata experiencias vividas, veinticinco años antes, junto al P. Isla o a la lejanía en el espacio y a la ingente labor intelectual y editorial que el polígrafo manchego llevaba desarrollando en la Romagna desde 1778, pero nunca a falta de interés por la vida y obra del admirado cofrade leonés. Al fin y al cabo, ambos fueron convencidos jesuitas, con muy semejante ideología de rancio jesuitismo, a pesar de su aparente adaptación a la sociedad de su tiempo, sin que pesasen demasiado los treinta y dos años de edad que generacionalmente los separaban.

\section{Apéndices}

\subsection{El artículo "ISLA, Josef Francisco de".}

"[107] ISLA, Josef Francisco de. Nació, a 24 de marzo 1703; en una pequeña aldea, Ilamada [Vidanes, cercana a la] $* * *^{13}$ Villa de Valderas, a la cual pasaron sus padres poco después al su nacimiento y, por eso, Isla en una nota al Compendio de la historia de España [de Duchesne], que tradujo, llama a Valderas nuestra adoptada patria. Su educación en la niñez correspondió a la nobleza y a las conveniencias de su casa. A los 16 años de edad, en el 1719, entró en Compañía de Jesús en el colegio de Villagarcía, que pertenecía a la provincia jesuítica de Castilla la Vieja, en el cual tuvo su noviciado y estudió la retórica. Habiendo concluido sus estudios de filosofía y teología, enseñó estas facultades en las ciudades de Santiago, Segovia y Pamplona. Fue predicador en varios colegios y, principalmente, en el de Valladolid, en que, ya de madura edad, corrigió algunas vivezas, y trasportes $* * *^{14}$ de su juvenil fantasía, y predicó

$13^{* * *}$ Reconstrucción del ms. roto.

14. Italianismo: "trasporto" tiene entre sus acepciones las de "arrebato, ahínco, pasión". 
con aquella elocuencia y espíritu que procuró después promover en los oradores sagrados. Se retiró al colegio de Villagarcía en que continuó a predicar, y compuso la Historia de Fr. Gerundio de Campazas, de la cual se hablará después.

Desde Villagarcía pasó al colegio de la Villa de Pontevedra, en Galicia, donde vivió hasta el 1767 en que salió de España. A1 intimarle su salida, recogió todas las cartas de sus superiores en que le daban algunos avisos y reprensiones y, poniéndolas sobre la mesa de su estudio, dijo a los seglares circunstantes: "Dejo aquí estas cartas, para que todo el mundo sepa que, si Josef de Isla ha cometido algunas faltas contra la perfección que en sus miembros pedía y mandaba la Compañía de Jesús, ésta no se las ha disimulado, antes bien sus superiores se las han corregido".

En el mismo día en que debía salir de Pontevedra para embarcarse en el puerto de La Coruña, le asaltó un violento accidente de perlesía que, dejándole libre la cabeza, le cogió la boca y la lengua. Hizo instancias para que le dejasen ir en compañía de los demás jesuitas con quienes salió de Pontevedra, y Ilegó a la villa de Caldas, tres leguas distante. En su arrivo le repitió el accidente. Hízosele prontamente una sangría con la que, habiendo logrado algún alivio, se puso en viaje al día siguiente y llegó a la ciudad de Santiago, en que el accidente descargó su tercer golpe con tan terrible fuerza que hizo temer de su vida. Se despachó pronto aviso al Capitán General de Galicia informándole del estado de Isla, por lo que resolvió que quedase en Santiago.

El día 14 de mayo, medio convaleciente, salió del puerto de La Coruña en el navío "San Juan Nepomuceno", cuyo capitán D. Josef de Beanes, o por recomendaciones de algunos amigos de Isla, que tenía muchos en España, o por atención a su mérito, le hizo la distinción de alojarlo en su cámara de popa y de tenerlo diariamente a su mesa. Después de tres meses de navegación, en que los jesuitas cruzaron los mares esperando el orden de su destino o desembarco, los del dicho navío desembarcaron en Calvi de Córcega. Esta ciudad, de puro nombre, es una infeliz aldea, en que había de guarnición algunos centenares de soldados franceses, que con estrechez y grande incomodidad vivían en las casas o chozas de los vecinos de Calvi. Desembarcaron más de seiscientos jesuitas, que andaban errantes por calles y por el campo buscando chozas o cuevas, en que pudiesen hallar, a lo menos, la habitación que logran tener algunas fieras.

Isla, en estas circunstancias, se acogió a una iglesia y en un rincón de ella se abandonó a la muerte que no podría evitar, o a la Providencia Suprema, que de ella le librase. E1 cura de la iglesia, cerrándola al anochecer, advirtió que Isla estaba en un rincón de ella y le avisó que saliese. Isla entonces respondió: "Saldré para dormir en la calle o en el campo, pues yo, achacoso, no encuentro ni una cueva en que pueda dormir". E1 cura, compadecido de la infelicidad y miseria de Isla, lo llevó consigo y le dio cama dentro del estrecho aposento 
en que él dormía. Con el dicho cura vivió Isla los 14 meses que estuvo en Calvi, desde donde en septiembre del 1768, con los demás jesuitas españoles, salió embarcándose para Génova, de donde pasó a los Estados Eclesiásticos y se estableció, a 15 de noviembre, en Crespelano (aldea entre Módena y Bolonia), alojándose con muchos jesuitas en un palacio campestre que pertenece al conde Grassi, senador de Bolonia. Informado este señor del mérito de Isla, le cedió para su habitación el hermoso apartamento que para su propia persona tenía reservado en el palacio.

Pasó, después de un año, a Bolonia, en donde por orden de su arzobispo, el señor cardenal Malvezzi, fue preso la noche del 8 de julio del 1773 y conducido por una numerosa escuadra de alguaciles a la cárcel pública del arzobispo, en la que estuvo 19 días, y después fue desterrado de Bolonia y confinado en Budrio, aldea dos leguas distante de ella. El motivo de esta prisión, como se dice en el erudito y voluminoso Jornal $* * *^{15}$ del luterano Cristóbal Gottlich bon Murr, fue una proposición dicha en pública conversación y con el mayor respeto a las determinaciones eclesiásticas en la causa de un venerable. Isla pagó al delator agenciando gran parte de la dote a una hija suya. Hasta aquí Murr, cuya relación es no menos cierta que pública en Bolonia, pues, en ésta, publicó la marquesa Tanara que Isla, a quien ella sumamente estimaba, la había empeñado para buscar la dicha dote con las siguientes expresiones: "Señora, otras veces me he valido del favor de $V$. Ex $x^{\underline{a}}$. para empeños en que me han metido, ahora me meto yo, y tan de recio que la gracia que le pido, la pido a V. Ex $x^{a}$. por cuanto hay de sagrado en cielo y tierra; y no desistiré hasta conseguirla, que se trata de hacer bien a un hombre que me ha hecho mucho mal". Este hombre era el genovés $M$. empleado por la corte española en la comisión sobre los jesuitas españoles en Italia, el cual estimuló a otro comisionado C[oronel]. para que se hablase al cardenal Malvezzi y este encarcelase pública y repentinamente a Isla. Muchos políticos juzgaron que esta inhumana prisión se hizo también para apoderarse improvisadamente de los manuscritos de Isla, como en efecto sucedió. En ellos, ciertamente, no se halló cosa reprensible, pues, si se hubiera hallado, el más público y cruel castigo la hubiera publicado.

Isla fue después desterrado de Bolonia y con el destierro se pretendió cubrir el desacierto de la prisión de un literato virtuoso, respetado y admirado en Bolonia, y visitado de los primeros literatos que, viajando, pasaban por ella. En 1775 el señor cardenal Gioannetti, sucesor del cardenal Malvezzi, a instancias de muchos nobles de Bolonia permitió a Isla que a ella volviese, y el respetable anciano en ella encontró casa, como propia, en el palacio de los condes Tedeschi, que en él le tuvieron y asistieron como a hermano hasta su muerte, sucedida a 2 de noviembre 1781. La condesa Tedeschi le hizo decentísimo funeral a 4 de noviembre en la parroquia de Santa María Muratele, en que está

$15^{* * *}$ Italianismo "giornale". Christoph. Gottlieh Murr, Journal zur Kunstgeschiche und zur allgemeinen Litteratur, Nürnberg, 1781 - 1783, en 8.ํㅜㅇ 
sepultado, e hizo que le sacasen 1 a cara en yeso para formar un busto al natural. Murr, en su obra citada, publicó el siguiente epitafio, que un correspondiente literario le había enviado ${ }^{16}$ :

D. O. M.

Josepho Francisco Islae

Natione Hispano, [genere nobili] ${ }^{* * *^{17}}$

Viro

Ingenii

Lepidi, foecundi, perpoliti,

Eleganti varietate amoenissimi.

Mentis

Amplae, sublimis, apertae,

Ad omnes scientias natura comparatae,

In omnibus fere excultae.

Judicii

Ad critices regulas plane compositi.

Rhetori urbanissimo,

Sacrae eloquentiae vindici festivissimo,

miris ubique laudibus celebrato.

Quem

Nunquam morosus fastidivit auditor,

Numquam fastidiet lector,

In patria oratoria Tullium,

In historia Livium,

In lyricis ac ludicris Horatium,

Dixeris.

Qui

Natus Villavidane in Legionensi regno

Die XXIV Martii Anni CICDCCIII

Eximia pectoris ingenuitate,

Ac inculpata morum probitate,

Intimis carus,

Exteris probatissimus.

Exul ex-jesuita

Rerum humanarum fluctibus dire vexatus,

Sed infractus animo

Inter ex-jesuitas exules

Pie obiit

Bononiae die I/ Novembris

Anni Domini CICDCCLXXXXI

Amici moerentes

P.

Isla era dotado de talento grande y propio para ser excelente en todo género de ciencias; su fantasía era sobresaliente, y, si de ella se hubiera dejado arrastrar, hubiera inundado la república literaria de romances, poesías y de otras obras de placer y amenidad, no inferiores a las más celebradas en este género.

16. Corregido en el ms.: "había mandado".

$17^{* * *}$ Falta en Hervás. 
Los superiores de Isla juzgaron no ser combinable el desahogo de su gran talento poético con la continua ocupación de los ministerios apostólicos y del magisterio de ciencias sagradas; y por esto, únicamente, no dejaron de darle algunos avisos de corrección. Enseñó con aplauso filosofía y teología. Tuvo conocimiento perfecto de varias lenguas eruditas, y leyó sus más insignes autores. Escribió muchas obras, que dejó inéditas, mas se ignoran $* * *{ }^{18}$ su paradero, y aún títulos.

Un amigo suyo [Murr] le redujo pocos días antes de su muerte a hacer catálogo de sus manuscritos, mas él [Isla] murió antes de empezar a dictarlo. Se sabe que en España había escrito más de ocho tomos sobre el carácter y las providencias de los parlamentos de Francia, obra que se admiraría como la historia políticamente profética del miserable estado actual de Francia. Hasta la edad de 50 años escribió muchos opúsculos poéticos, cuyo paradero se ignora. Escribió tratados críticos y algunos de estos (según pública fama) estaban en la librería de D. Manuel de Munita en Madrid. Los manuscritos que le robaron en la prisión antes dicha, en el 1772 [sic, 1773], se entregaron al cardenal Malvezzi. Luego que Isla murió, la condesa Tedeschi dio a sus criados algunos papeles escritos para que los quemasen en el patio de su palacio.

Dos meses después de la muerte de Isla, se presentó a dicha condesa el señor D. Manuel de Laforcada, comisario real en Bolonia e intendente de los jesuitas, pidiendo los manuscritos en nombre de su corte, y la condesa respondió que sus criados eran testigos de haber sido quemados. En Bolonia se creyó y se dijo públicamente que la condesa había ocultado los manuscritos de Isla. De las [obras] que este dio a pública luz, pongo aquí las escasas noticias, que he adquirido fuera de España.

1. Triunfo del amor y de la lealtad. Día grande de Navarra en la festiva, pronta y gloriosa aclamación del serenísimo católico Rei don Fernando II de Navarra y VI de Castilla, ejecutada en la Real Imperial Corte de Pamplona \&c. en el día 21 de Agosto 1747 (sic, 1746). En 4.‥ Esta obra anónima se reimprimió algunas veces. Murr citado, hablando de ella, dice que "se tuvo por sátira contra los navarros. Que Isla se defendió, y fue aceptada y aprobada su defensa; y que después volvió a prevaler la opinión de haber sido satírica la dicha obra". Estas mismas cosas oí yo contar en España.

2. Historia del famoso predicador Frai Gerundio de Campazas, alias, Zotes, escrita por el licenciado Don Francisco Lobón de Salazar, presbítero beneficiado de Preste en las villas de Aguilar y de Villagarcía del Campo. Tomo primero. Madrid, 1758. En la imprenta de D. Gabriel Ramírez. 4.․ .

De esta obra se imprimieron dos mil ejemplares, los cuales se vendieron en el día mismo en que ella se publicó. Se empezó a hacer la segunda edición,

$18^{* * *}$ Ms. roto. 
mas luego, por orden real, se suspendió su reimpresión y se prohibió imprimir los demás tomos. Constaba de seis tomos, según acuerdo haber oído del autor en el Lazareto de Génova, en el que por más de un mes estuvimos encerrados los jesuitas españoles. El autor, en los demás tomos, seguía la vida de Frai Gerundio haciéndole predicador fanático en varios conventos de su orden religioso. Le daba por algún tiempo la dirección de un convento de religiosas a las que encantaba con sus sermones, y, últimamente, con la experiencia y madurez que dan los años y con los avisos de religiosos sabios, lo proponía iluminado en la verdadera manera de anunciar la palabra divina. Se ignora el fin que hayan tenido los tomos de la vida de Fray Gerundio que el señor Isla dejó inéditos, mas no es creíble que hayan perecido.

El tomo publicado en Madrid se reimprimió varias veces en España. He visto una edición del año 1770, (que parece ser española), sin nombre, impresa sin señalar el lugar de la impresión. Asimismo he visto el tomo segundo publicado en el 1768 sin nombre de impresor, ni de lugar de impresión; mas ésta, a mi parecer, es española. El señor Isla, en dicho Lazareto de Génova, tuvo noticia de este tomo segundo y dijo que no lo reconocía por producción suya. Se conjetura que dicho tomo segundo se imprimió según un manuscrito poco correcto de Isla.

Los dos tomos dichos, traducidos en inglés, se imprimieron en Londres con el siguiente título: The history of the famous preacher friar Gerund de Campazas otherwise Gerund Zotes, translated from the spanish in two volumes. London. 1772. Printed for J. Davies. Volúm. 2, en $8 .^{\circ}$ grande. En esta edición el traductor dejó la crítica contra el Barbadiño y algunos episodios. Al principio del primer tomo el traductor pone un largo discurso y en él se dice: "En una relación que acompañaba al original de esta obra, se lee que la Historia de Frai Gerundio se publicó en Madrid el 1758 con el nombre de Francisco Lobón de Salazar por Josef Francisco Isla, jesuita, con la loable intención de corregir los abusos del púlpito español, haciendo ridículos a los malos predicadores. Que esta obra se condecoró con la aprobación de los primeros literatos de España, a los que se había comunicado manuscrita. Que los mismos inquisidores animaron al autor a su publicación, y por escrito atestiguan sus alabanzas. Que uno de los inquisidores había dicho ser absolutamente necesario este medio, ya que las buenas providencias eran, por experiencia, ineficaces para reformar el abuso de la oratoria sagrada; y que el cáustico y el corrosivo debían usarse cuando la cangrena no cedía a los remedios suaves, mas, no obstante la aprobación de la Inquisición y de los principales literatos de la clerecía española, se prohibió el tomo impreso en Madrid \&".

El traductor advierte que el primer tomo correspondía al que en Madrid se había publicado y que el segundo se había traducido según ciertos manuscritos que se habían logrado. De esta advertencia se infiere que en España se habían hecho diversos traslados [copias] del segundo tomo inédito de la Vida de 
Frai Gerundio. A los jesuitas españoles se intimó a media noche el decreto de su expulsión, y después de la intimación todos quedamos presos sin poder salir de la sala o capilla en que se nos intimó el decreto. Después, sucesivamente, todos fuimos Ilamados para tomar, a presencia del juez ejecutor, el solo vestuario que teníamos y el breviario (los que eran sacerdotes), por lo que debimos dejar casi todos los manuscritos en nuestros respectivos aposentos. De los que yo tenía, pude con industria tomar una obra intitulada Viaje a los reinos de Plutón, que hicieron, \& y, en el registro que me hicieron en Cartagena, al embarcarme, me lo quitaron. Probablemente al señor Isla sucedió lo que casi a todos: él dejaría sus manuscritos en su aposento del colegio de Pontevedra, en que residía, o si los pudo sacar los perdería en el nuevo registro que a los jesuitas se hizo al embarcarse; y en esta ocasión se hicieron diversos traslados del tomo segundo que se publicó en Inglaterra y en otros reinos.

Contra el primer tomo de la vida de Frai Gerundio, publicado en Madrid, D. Josef Maimó y Ribes y un religioso capuchino, Ilamado Marquina, escribieron cartas satíricas, cuya impresión no permitió el gobierno. Isla respondió a dichas cartas con otras cuatro cartas que podrían formar un volumen en 4.․ De estas cuatro cartas se hicieron muchos traslados en España.

Sempere y Guarinos, en su Biblioteca española, habla de estas cartas y cita al marqués de Caraccioli que elogia la Historia de la vida de Frai Gerundio. Esta historia se cita con elogio por Pablo Ernesto Jablonki en el \$ 4, sección 2 del volumen $3 .^{\circ}$, de sus Instituciones de la historia cristiana, impresas en Francfort el 1766 .

3. Compendio de la historia de España, escrito en francés por el jesuita Duchesne, y traducido por el P. Francisco de Isla con algunas notas críticas. Madrid, 1764. Por Joaquín Ibarra. 8.․․ vols. 2.

4. Cartas de Juan de la Encina. Obra del P. Josef de Isla contra un libro que escribió Don Josef de Carmona, cirujano de Segovia, intitulado: "Método racional de curar sabañones". Segunda edición. Madrid 1784. Por Pantaleón Aznar. 8..

5. Reflexiones cristianas sobre las grandes verdades de la fe y sobre los principales misterios de la Pasión de N. S. Jesu-Cristo. Madrid, 1785. Por Joaquín Ibarra. 8..

6. Cartas familiares del P. Josef Francisco de Isla, escritas a su hermana doña María Francisca de Isla y Losada, y a su cuñado don Nicolás de Ayala. Madrid, 1785. En la imprenta del Consejo de Indias, 8. ํ, vols. 4.

7. El héroe español: historia del emperador Teodosio el Grande, sacada de la que dio a luz en lengua francesa Monseñor Flechier, Obispo de Nimes, traducida por el P. Francisco de Isla. Madrid 1789. 8. ํ, volums. 2.

8. Sumario de la historia eclesiástica y de la de España, en verso, por el P. 
Josef Francisco de Isla. Segunda impresión, 1789. Por los libreros Escribano y Guillón.

9. Año cristiano. Se ha impreso dos veces en Madrid, en doce tomos en 8.․․ Esta obra es traducción de la que en francés escribió el Jesuita Croiset. Isla tradujo los once tomos primeros de ella.

10. Colección de papeles crítico-apologéticos, que en su juventud escribió el P. Francisco Isla contra el doctor don Pedro de Aquensa y el bachiller Don Diego de Torres en defensa del R. P. Benito Feixoo y del doctor Martín Martínez. En 8.․

11. Vida y hechos de Blas Gil de Santillana; traducción del francés. 4 volúm. en $8 .^{\circ}$.

12. Cartas de Constantino Pupini, traducidas del italiano. Son varios tomos que se imprimían en Madrid.

\section{Manuscritos:}

De estos, pocas noticias particulares se pueden dar, porque las circunstancias críticas del señor Isla le obligaron a ocultarlas $* * *{ }^{19}$ celosamente. Entre los manuscritos debemos contar con certidumbre los siguientes.

1. Sobre el carácter de los parlamentos de Francia. Ocho tomos.

2. Crítica de la carta pastoral que monseñor Dn. Josef Rodríguez de Arellano, Arzobispo de Burgos, publicó en ocasión de la expulsión de los jesuitas españoles. Tres tomos.

3. Historia de Frai Gerundio. Seis tomos.

4. Vida y hechos de Gil Blas de Santillana, traducción del francés al español. Volúm. 4. En 8. $\stackrel{\text {. }}{ }$

5. Algunos tomos de obras, ya poéticas y ya satíricas, contra personas irreligiosas o de religión dudosa".

\section{El artículo "ISLA, Ramón de", el hermano jesuita}

"[108] ISLA, Ramón. Hermano de Josef Francisco. Nació en Villavidanes (sic), patria también de Josef Francisco, y al salir de la pubertad fue recibido en la provincia jesuítica de Castilla. Estudiando filosofía y teología se instruyó perfectamente en los ramos principales de crítica en las ciencias sagradas y eclesiásticas, en las que por su elevado ingenio hubiera hecho extraordinarios

19*** Posible anacoluto, ya que el pronombre "las", debería referirse a "los manuscritos". 
progresos si en la más fresca edad no hubiera desaparecido. Habiendo profesado solemnemente y enseñando la filosofía en Segovia, murió el 1764 por enfermedad contagiosa contraída asistiendo a un regimiento que había estado en las guerras con Portugal. Imprimió discursos anónimos sobre la Historia de Frai Gerundio".

\section{Fuentes y Bibliografía citadas}

ADS (Archivo Diocesano de Salamanca), Libro Becerro de las órdenes generales y particulares, menores y mayores que el Ilustrísimo Señor Don Silvestre García Escalona, por la Gracia de Dios y de la Santa Sede Apostólica obispo de esta ciudad de Salamanca, del Consejo de Su Magestad, celebró en su capilla episcopal y oratorio privado.... Años 1714-1729, sig. C-2-4.

AGS (Archivo General de Simancas), Estado, leg. 5650.

AGUILAR PIÑAL, Francisco. 1986. Bibliografía de Escritores del siglo XVIII, t. IV, Madrid, n. 4202 al 4607.

ALBORG, Juan Luis. 1975. Historia de la Literatura Española, Madrid, Gredos, vol. III, pp. 255-290.

ÁLVAREZ BARRIENTOS, Joaquín. 1991. "Introducción" a José Francisco de ISLA, Historia del famoso fray Gerundio de Campazas, alias Zotes, Barcelona, Clásicos Universales Planeta, pp. XI-XXII. Edición, introducción y notas de Joaquín Álvarez Barrientos.

AMAAEEM (Archivo del Ministerio de Asuntos Exteriores de Madrid), Santa Sede, leg. 222 (Reales Órdenes de 1773); leg. 486.

ASTORGANO ABAJO, Antonio. 1999. "La personalidad del ilustrado Don Nicolás Rodríguez Laso (1747-1820), inquisidor de Barcelona y Valencia", en Revista de la Inquisición de la Universidad Complutense, n. .9 (año 1999), pp. 119-190).

—. 2000. "El Fiscal Inquisidor don Nicolás Rodríguez Laso en Barcelona (17831794)", en Boletín de la Real Academia de Buenas Letras de Barcelona, vol. XLVII, 1999 - 2000, pp. 197 - 276.

—.2003a. "El mecenazgo literario de Campomanes y los jesuitas expulsos", en Actas del Congreso Internacional sobre Campomanes, Instituto Feijoo, Oviedo, 2003.

-2003b. "Hervás, apologista del eusquera como lengua primitiva de España en sus contextos fuerista y vascoiberista", en Archivo de Filología Aragonesa, Año 2003. Homenaje a Manuel Alvar, Institución Fernando el Católico, Zaragoza, 2003. En proceso de publicación. 
—. 2003c. "Hervás, la Bascongada y los lingüistas defensores del vacoiberismo, en el marco del fuerismo", en Boletín de la Real Sociedad Bascongada de Amigos del País, San Sebastián, 2003.

- 2004. "La Biblioteca jesuítico-española de Hervás y su liderazgo sobre el resto de los ex jesuitas", en Revista de Historia Moderna de la Universidad de Alicante. Año 2004. En proceso de elaboración.

BARETTI, G. 1980. Prefazioni e polemiche, Bari, Laterza, "Prefazione alla Historia", trad. de E. SORIANO PÉREZ-VILLAMIL, en España vista por historiógrafos y viajeros (1750-1799). Madrid, Narcea, 1980.

—. 1771. Proposal for publishing by subscription a complete edition of the "Historia de fray Gerundio», Londres.

- 1786. Tolondron. Speeches to John Bowle about his edition of Don Quixote. London, 1786

BELLETTINI, Pierangelo. 1998. "Tipografi romagnoli ed ex gesuiti spagnoli negli ultimi decenni del Settecento", en Il libro in Romagna. Produzione, commercio e consumo dalla fine del secolo XV all'età contemporanea. Convegno di studi (Cesena, 23-25 marzo 1995), a cura di Lorenzo Baldacchini e Anna Manfron, Firenze, Leo S. Oposchki, 1998, pp. 557-657.

CHEN SHAM, Jorge. 1999. Fray Gerundio de Campazas o la corrupción del lenguaje. Sátira y escamoteo autorial, Editorial de la Universidad de Costa Rica, San José.

DIOSDADO CABALLERO, Ramón. 1814. Bibliothecae scriptorum Societatis Jesu. Supplementum primum. Romae 1814. Apud Franciscum Bourlié.

EGUÍA RUIZ, Constancio. 1932. "Postrimería y muerte del P. Isla en Bolonia, su testamento hológrafo". Razón y Fe 100 (1932), pp. 305-321 y en Razón y Fe 101 (1933), pp. 41-61.

—.1947. "El Padre Isla, tan buen religioso como literato: historia verídica de su espíritu". Razón y Fe 136, pp. 229-41.

—.1948a. "El autor del FGC expulsado de España (1767)". Hispania 8, pp. 43455.

—. 1948b. "El Padre Isla en Córcega", en Hispania 8, pp. 597-611.

—. 1951. "El estilo humanístico del autor del FGC". Humanidades Comillas 3.2 , pp. 263-76.

-1955. "La predilecta hermana del Padre Isla y sus cartas inéditas". Humanidades Comillas 7.2, pp. 255-268.

FERNÁNDEZ, Luis, S.I. 1978. ed. del FG, t. I, Madrid, Ed. Nacional. Introducción, pp. 1-53. 
GARCÍA ABAD, Albano. 1969. "Correcciones y nuevos datos sobre la biografía del padre Isla (1703-1801)", en Revista de Literatura, n. 35, Madrid, pp. 39-55.

GAUDEAU, Bernard. 1891. Les prêcheurs burlesques en Espagne au XVIII.e siècle. Étude sur le P. Isla, París, Retaux-Bray, XXIII + 568 pp.

GIMÉNEZ LÓPEZ, Enrique. 1997a. “La apología del jesuitismo en el exilio: el P. Isla en Italia", en Disidencias y exilios en la España Moderna, Alicante, pp. 573-607.

- y Mario MARTÍNEZ GOMIS. 1997b. “Un aspecto logístico de la expulsión de los jesuitas españoles: la labor de los comisarios Gerónimo y Luis Gnecco (1767-1768)", en Enrique Giménez López (ed.), Expulsión y exilio de los jesuitas españoles, Alicante, pp. 181-195.

- y Mario MARTíNEZ GOMIS. 1996. "El Padre Isla en Italia". En Españoles en Italia e italianos en España. IV Encuentro de investigadores de las Universidades de Alicante y Macerata (mayo, 1995). Enrique Giménez, Miguel A. Lozano y Juan A. Ríos (eds.), Alicante, Departamento de Filología Española, Departamento de Historia Medieval y Moderna, pp. 13-26. Reproducido en Enrique Giménez López (ed.), Expulsión y exilio de los jesuitas españoles, Alicante, 1997, pp. 347-360.

HERRERO, Javier. 1971. Los orígenes del pensamiento reaccionario español, Cuadernos para el diálogo, Madrid, pp. 151-181, Capítulo "Hervás contra la Revolución".

HERVÁS Y PANDURO, Lorenzo. Cartas, BNM, ms. 22996.

- 1789. Historia de la vida del hombre. Su autor el abate don Lorenzo Hervás y Panduro, socio de la Real Academia de las ciencias y antigüedades de Dublín y de la Etrusca de Cortona. Tomo II. Parte I. "Pubertad y juventud del hombre". Madrid, Imprenta de Aznar, 1789.

-. 1807. Causas de la Revolución de Francia en el año de 1789, y medios de que se han valido para efectuarla los enemigos de la Religión y del Estado. Obra escrita en Italia por el Abate D. Lorenzo Hervás, Bibliotecario de N. SS. P. Pío VIII, en carta que dirigió desde Roma a un respetable ministro del Consejo de Castilla, Madrid, 1807. Edición clandestina de 1803.

—. 1793a. Biblioteca jesuítico-española de los escritores que han florecido por siete lustros. Estos empiezan desde el año de 1759, principio del reinado del Augusto Rei Carlos III y acaban en el 1793. Manuscrito muy deteriorado, conservado en el Santuario de Loyola. Edición crítica de Antonio Astorgano. Diputación de Cuenca, en proceso de elaboración.

- 1793 b. Viaje estático al mundo planetario, en que se observan el mecanismo y los principales fenómenos del cielo; se indican sus causas físicas y se 
demuestran la existencia de Dios y sus admirables atributos, Madrid, Imprenta de Aznar, 1793, vol. II.

ISLA, Francisco José de. 1979. Anatomía del Informe de Campomanes. Prólogo y notas del P. Conrado Pérez Picón, León, 1979.

—. 1989. Apología por la Historia de Fray Gerundio. Edición de José Jurado.— Madrid, Fundación Universitaria Española, 177 pp. (Clásicos olvidados, 9).

-. 1992. Historia del famoso predicador fray Gerundio de Campazas, alias Zotes. Edición crítica de José Jurado. Edit. Gredos, Madrid.

-. 1999. Historia de la expulsión de los jesuitas. (Memorial de las cuatro provincias de España de la Compañía de Jesús desterradas del Reino, a S. M. el rey Don Carlos III). Estudio introductorio y notas de Enrique Giménez López. Alicante, Instituto de Cultura «Juan Gil-Albert», 245 pp. (Col. «Espejo de Clío», 12).

JURADO, José. 1982. «Ediciones 1758 del Fray Gerundio de Campazas», en Thesaurus, 37, pp. 544-580.

—. 1985. «Ediciones tempranas del Fray Gerundio de Campazas», en Bulletin Hispanique, 87, 1985, pp. 137-165.

—. 1992. "Introducción y notas" a ISLA, Francisco José de. 1992. Historia del famoso predicador fray Gerundio de Campazas, alias Zotes. Edición crítica de José Jurado. Edit. Gredos, Madrid.

LATASSA, Félix de. 1885. Biblioteca antigua y nueva de los escritores aragoneses de Latassa, aumentada en forma de diccionario biográfico-bibliográfico por don Miguel Gómez Uriel, Zaragoza.

LEGARDA, Anselmo. 1955. "Donostierras del siglo XVIII vistos desde el púlpito del P. Isla", en Boletín de la Real sociedad Vascongada de Amigos del País, Año XI, cuaderno 1.․, San Sebastián, pp. 61-73.

LUENGO, Manuel, Diario. Varios tomos passim desde el I (año 1767) al XXVII2 (año 1793).

-, Noticias Literarias sacadas textualmente del Diario del P. Luengo. Años 1791-1796, t. 4.ํ, p. 195 (MONASTERIO DE LOYOLA, Escritos, Caja $37 / 01)$.

—, Papeles varios, XV. (MONASTERIO DE LOYOLA).

- 2002. Memorias de un exilio. Diario de la expulsión de los dominios del Rey de España (1767-1768), Publicaciones de la Universidad de Alicante, Alicante. Edición de Inmaculada Fernández Arrillaga.

MARTÍNEZ DE LA ESCALERA, José. 1981. "Primeros escritos del Padre Isla (1721-31) y un catálogo de sus obras (1774)", Miscelánea Comillas, 49, pp. 
149-81.

- 1994. "Introducciones" a José Francisco de Isla: Crisis de los predicadores y de los sermones y otros escritos (1725-29), Universidad Pontificia de Comillas, Madrid, 1994.

MARTÍNEZ GOMIS, Mario. 1997. "Los problemas económicos y de habitación de los jesuitas españoles exiliados en Córcega (1767-1768)", en Disidencias y exilios en la España Moderna, Antonio Mestre Sanchís y Enrique Giménez López (eds.), Alicante, pp. 679-690.

MERCADIER, Guy. 1995. "Dos trayectorias novelescas", en Historia de la Literatura Española, IV. Siglo XVIII. Jean CARAVAGGIO (dir.), Barcelona, Ariel, 1995, pp. 60-66.

MONLAU, Pedro Felipe (ed.). 1850. José Francisco de Isla. obras escogidas. Con una noticia de su vida y escritos, Madrid, La Publicidad; reimpr. en BAE, t. XV, Madrid, Ribadeneyra, 1850, XXXVII + 632 pp. Citado como BAE, $X V$.

MURR, Christoph. Gottlieh. 1781. Journal zur Kunstgeschiche und zur allgemeinen Litteratur, Nürnberg, 1781 - 1783, en 8.ํㅜㅇ

OLAECHEA, Rafael. 1983. "Perfil psicológico del escritor J. F. de Isla (170381)", en El Padre Isla: su vida, su obra, su tiempo, León, 1983, pp. 101-119. También en el Boletín del Centro de Estudios del siglo XVIII (Oviedo), 9, 1981, pp. 3-26.

PÉREZ PICÓN, Conrado. 1964. "El Padre Isla vascófilo. Un epistolario inédito", Miscelánea Comillas, 42, 1964, pp. 183-301; 43, 1965, pp. 342-505.

—. 1981. "El Padre Isla, un gran desconocido", en Razón y Fe, n. 998, pp. 458484.

—. 1983. Un colegio ejemplar de letras humanas en Villagarcía de Campos (1576-1767).

PINTA LLORENTE, Miguel de la. 1979. "El P. José Francisco de Isla en el Santo Oficio", en Humanismo e Inquisición t. I Madrid, Estudios Agustinianos, pp. 33-56.

PORTILLO, Enrique de. 1909. "Lorenzo Hervás. Su vida y sus escritos (17351809)", Razón y Fe XXV (1909); XXVI, XXVII, XXVIII (1910); XXIX, XXX, XXXI (1911); XXXII y XXXIII (1912).

REAL ACADEMIA DE LA HISTORIA, Inquisición, Consejo de la, Expediente instruido sobre la Historia del Predicador Fray Gerundio, Madrid, 1758-1760; ms. 9-27-5-E-150, 501 fols. con algún folleto. Inédito.

SALA VALLDAURA, Josep María.1995. “La poesía contrarrevolucionaria (1793- 
1795): Forner, el conde de Noroña y González del Castillo", en Revista de Literatura, LCII, n. ${ }^{\circ}$ 114, Madrid, pp. 477-501.

SEBOLD, Russell P. 1960. "Introducción" a J. F. de ISLA: Fray Gerundio de Campazas. Edición, introducción y notas. Madrid, Espasa.-Calpe, 19601964, 4 vols. (introducciones en t. I, pp. XCVIII y en t. III, pp. XVIII); reimpresión en 1969-1973.

SEMPERE Y GUARINOS, Juan. 1786. "José Francisco de Isla". Ensayo de una Biblioteca Española de los mejores escritores del Reinado de Carlos III. Madrid: Imprenta Real, vol. III, pp. 123-131.

SOMMERVOGEL, Charles, et alii. 1893. "José Francisco de Isla», Bibliothèque de la Compagnie de Jésus. Nouvelle édition, t. IV, Bruselas, Oscar Schepens; París, Alphonso Ricard, 1893, cols. 655a-686b.

TOLRÁ, Juan José [peudónimo Josef Ignacio de Salas]. 1803. Vida del padre Isla, Madrid, Viuda de Ibarra.

URIARTE, Eugenio Eulogio de.1904. Catálogo razonado de las obras anónimas y seudónimas de autores de la Compañía de Jesús, pertenecientes a la antigua Asistencia de España, Madrid, 1904-1916.

VV. AA, El padre Isla: su vida, su obra, su tiempo, León, Institución Fray Bernardino de Sahagún, 1983.

ZARCO CUEVAS, Julián. 1936. Estudios sobre Lorenzo Hervás y Panduro, Madrid. 